"Declaration of interest: none"

\title{
2 Spinach leaf and chloroplast lipid: A natural rheology modifier
}

\section{3 for chocolate?}

4 Nizaha Juhaida Mohamad ${ }^{\mathrm{a}, \mathrm{b}, *}$, David Gray $^{\mathrm{b}}$, Bettina Wolf ${ }^{\mathrm{b}, 1}$

5 aniversiti Malaysia Terengganu, Faculty of Fisheries and Food Science, 21030 Kuala Nerus, Terengganu,

$6 \quad$ Malaysia

$7 \quad{ }^{b}$ Division of Food, Nutrition and Dietetics, University of Nottingham, Sutton Bonington Campus, Loughborough

8 LE12 5RD, United Kingdom

$9 \quad *$ Corresponding author.

10 E-mail address: niezaju@umt.edu.my

11 'Present address: School of Chemical Engineering, University of Birmingham, Birmingham B15 2TT, United

12 Kingdom

Abstract

In this study the possibility of replacing current surfactants in chocolate formulations with natural lipids extracted from spinach leaf (SPLIP) or spinach chloroplast (CH.SPLIP) was evaluated. SPLIP and CH.SPLIP were extracted with chloroform/methanol following enzyme deactivation with hot isopropanol. Results showed a higher extraction yield for SPLIP while

19 glycolipids were more concentrated in CH.SPLIP. Sugar/oil suspensions with dispersed

20 volume fractions of $0.28,0.33$ and 0.37 containing $0.1 \%$ to $0.7 \%(\mathrm{w} / \mathrm{w})$ surfactant (SPLIP,

21 CH.SPLIP, lecithin and PGPR as commercial references) based on oil phase were prepared and analyzed in shear rheology. Apparent viscosity at $40 \mathrm{~s}^{-1}$ was significantly lower for the natural surfactants compared to lecithin at 0.5 to $0.7 \%(\mathrm{w} / \mathrm{w})$ addition. With regard to yield

24 stress, taken as the shear stress at $5 \mathrm{~s}^{-1}$, both natural surfactants showed comparable

25 performance to PGPR at $0.3 \%$ to $0.7 \%$ addition. As SPLIP and CH.SPLIP behaved similar 
26 ( $p>0.05)$, SPLIP, due to higher extraction yield, would be the preferred choice for

27 application in chocolate matrices.

Keywords: Chocolate, suspension rheology, lecithin, polyglycerol polyricinoleate (PGPR),

30 interfacial tension, natural surfactant

\section{Introduction}

Chocolate represents a high internal phase volume suspension with sugar and cocoa particles suspended in cocoa butter (CB). The rheological properties of chocolate are not only important in manufacturing steps (Servais, Ranc, \& Roberts, 2003) but also to give good quality eating properties (Beckett, 2008). Chocolate is characterized by a shear thinning viscosity behavior with yield stress. The yield stress denotes the transition between pseudosolid and pseudo-liquid behavior, and it can also be understood as the minimum shear stress at the first evidence (onset) of flow (Doraiswamy et al., 1991). The shear thinning properties are important for pumping and sensory characteristics (Beckett, 2008; Goncalves \& Lannes, 2010). The International Office of Cocoa (IOC) recommends the characterization of the rheological properties of chocolate between 2 and $50 \mathrm{~s}^{-1}$ by ramping shear rate up and down in 3 min respectively, with one minute holding at $50 \mathrm{~s}^{-1}$. The whole procedure should be preceded by a pre-shear step at $5 \mathrm{~s}^{-1}$ for 5 min (Afoakwa, Paterson, Fowler, \& Vieira, 2009; Servais et al., 2003).

The rheological properties of chocolate are influenced by the interactions between the dispersed solid sugar and cocoa particles in the CB continuous phase. Sugar particles have a hydrophilic surface and, therefore, are prone to aggregate if no surfactants added to the

49 lipophilic continuous phase. Aggregation leads to entrapment of CB thereby apparently increasing the particle volume fraction, increasing yield stress and apparent viscosity. Hence, 
a surfactant is added to coat the surface of the sugar particles so they disperse well in the continuous $\mathrm{CB}$ phase.

Depending on the type of chocolate, commercial chocolate contains around $29-40 \%$ (w/w) fat (Beckett, 2009) and $0.3-0.5 \%(w / w)$ surfactant (Beckett, 2008). The most commonly used surfactants are lecithin and polyglycerol polyricinoleate (PGPR). Lecithin promotes apparent viscosity reduction while PGPR decreases the yield stress without significantly affecting the apparent viscosity. Therefore, these two surfactants are often combined to obtain the desired product rheology (Schantz \& Rohm, 2005). Contrary to lecithin, naturally produced from the by-product of oil refining (van Nieuwenhuyzen, 2010), PGPR is chemically synthesized through polyesterification of glycerol and ricinoleic acid from castor oil (Christiansen, 2014). Both surfactants are assigned an E-number and are thus not considered clean-label. Consumers are often familiar with lecithin and likely to accept its presence in processed foods. PGPR on the other hand creates negative associations due to its complicated name and the fact that it is a synthetic material appears to be widely known among health-conscious consumers (Osborn, 2015).

Efforts to replace PGPR with a natural alternative date back some 30 years when a patent on the polar lipid fraction of oats, specifically the glycolipid fraction, as a low shear viscosity reducing agent in chocolate was published (Evans, Jee, Sander, Smith, \& Gibson, 1991). Depending on oat species and variety, $10-34 \%(\mathrm{w} / \mathrm{w})$ of the total oil was reported to constitute polar lipids, mainly glycolipids $(5-15 \%(\mathrm{w} / \mathrm{w}))$ and phospholipids $(5-26 \%$ (w/w)) (Doehlert, Moreau, Welti, Roth, \& McMullen, 2010; Sahasrabudhe, 1979; Youngs, Puskulcu, \& Smith, 1977). The main components of the glycolipid fraction were identified as galactolipids including digalactosyl diacylglycerol (DGDG), $41.5 \%(\mathrm{w} / \mathrm{w})$, and monogalactosyl diacylglycerol (MGDG), $18.5 \%(\mathrm{w} / \mathrm{w})$. Other glycolipids were present at a level of less than $10 \%(\mathrm{w} / \mathrm{w})$ (Sahasrabudhe, 1979). The phospholipid fraction was identified 
as containing phosphatidyl choline (PC), phosphatidyl ethanolamine (PE) and a minor fraction of phosphatidyl inositol (PI) (Doehlert et al., 2010; Kaimainen et al., 2012). To the best of the authors' knowledge, this research on oat oil has not been validated with alternative natural lipid extracts rich in the main oat lipid components, which motivated the present study.

MGDG and DGDG are also abundantly available in photosynthetic plants, in particular spinach (Spinach oleracea L.) which is therefore often selected as an exemplary photosynthetic plant in studies related to plant based polar lipids (Allen, Good, Davis, Chisum, \& Fowler, 1966; Douce, 1974; Douce, Holtz, \& Benson, 1973; Jaime et al., 2015). Other lipids found in spinach include the sulfolipid sulfoquinovosyl diacylglycerol (SQDG) (Christie, 2012), and the phospholipids phosphatidylglycerol (PG) and phosphatidylcholine (PC) (Mazliak, 1977). Galactolipids are neutral lipids while SQDG and PG each carry one negative charge in their head group (Dörmann \& Benning, 2002).

This study presents data on the composition and efficacy as fat based suspension rheology modifier of lipid extracted from both spinach leaf and spinach chloroplast. The polar lipid fraction of either has been reported to show little compositional difference (Dörmann, 2013; Wintermans, 1960), but extraction yield will be higher from isolated chloroplast due to their enrichment in lipids. Chloroplast isolation comprises an additional processing step, hence, in potential future commercial application, leaf lipid may be of higher value despite the lower extraction yield. Here, the performance of both lipids was compared to lecithin and PGPR as commercially applied surfactants, using sugar/oil suspensions, a common fat based food suspension model of chocolate.

\section{Materials and methods}

\subsection{Materials}


Fresh spinach leaves, icing sugar and sunflower oil were bought from a local supermarket. The moisture content of the fresh spinach leaves was, on average, $94.0 \pm 0.2$ $\mathrm{g} / 100 \mathrm{~g}$ (wet basis), determined by oven drying to constant weight at $105^{\circ} \mathrm{C}$. Icing sugar was used to prepare the sugar/oil suspensions and its properties relevant to this study are reported in section 2.8. Sunflower oil, as the suspension medium, was purified to remove any surface active molecules by adsorption to magnesium silicate (Florisil®, Sigma-Aldrich, Dorset, UK), as described in section 2.6. PGPR 90 was provided by Danisco (Kettering, UK), lecithin was from ADM (Hull, UK) and CB was from Barry Callebaut (Banbury, UK). Extraction solvents were chloroform (Sigma-Aldrich, UK), methanol (Fisher Scientific, Loughborough, UK) and isopropanol (Fisher Scientific, Loughborough, UK). Other materials included sodium chloride (Sigma-Aldrich, USA), sucrose (Sigma-Aldrich, USA) and deionized water. Further materials used by an external laboratory for lipid analysis are mentioned with the method.

\subsection{Lipid extraction from spinach leaf}

A heat pre-treatment with hot isopropanol was carried out prior to leaf lipid extraction, to prevent the activity of hydrolytic enzymes, which are easily activated when plant cells are ruptured (Benson, 1964; Fishwick \& Wright, 1977; Kates \& Eberhardt, 1957). The pre-treatment followed the method of Yao, Gerde, and Wang (2012) where $100 \mathrm{~g}$ of fresh leaves was finely homogenized in $300 \mathrm{ml}$ of pre-heated isopropanol $\left(80^{\circ} \mathrm{C}\right)$, using a glass household blender (kMix BLX50BK, Kenwood, UK) for 1 min. The mixture was then poured into a beaker and heated at $80{ }^{\circ} \mathrm{C}$ for $20 \mathrm{~min}$ while stirring at $400 \mathrm{rpm}$ on a magnetic hot plate stirrer. Treated leaf and solvent containing isopropanol soluble lipids were separated by filtering through three layers of cheesecloth on a Buchner funnel aided by vacuum suction. 
125 The filtrate was retained for lipid recovery and combined with the filtrate from the following 126 lipid extraction step.

Lipid extraction was following the established method of Folch, Lees, and Sloane-

128 Stanley (1957). The treated leaf collected from the heat pre-treatment procedure was mixed

129 with $240 \mathrm{ml}$ of chloroform/methanol $(2: 1, \mathrm{v} / \mathrm{v})$ and stirred on a magnetic plate stirrer at 400 rpm for $20 \mathrm{~min}$ (Folch et al., 1957). Following the filtration procedure as previously described, the extract was filtered and the filtrate was combined with that extracted from the heat pre-treatment. Solvents in the combined extracts were evaporated at $40{ }^{\circ} \mathrm{C}$ until almost dry. The extract was then reconstituted with $24 \mathrm{ml}$ of chloroform/methanol (2:1, v/v), transferred into a separatory funnel and $6 \mathrm{ml}$ of $\mathrm{NaCl}(0.9 \%$; w/v) solution was added for the final mixture to be close to $8: 4: 3$ (v/v) of chloroform/methanol/ $\mathrm{NaCl}$ (Folch et al., 1957). The extract was left to stand for at least $1 \mathrm{~h}$ until complete separation of the two liquids was visible. The upper phase contained all of the non-lipid substances and negligible amounts of lipids while the lower phase contained essentially all of the tissue lipids (Folch et al., 1957). The lipid phase was then transferred into a clean, pre-weighed flask. The solvent was evaporated at $40{ }^{\circ} \mathrm{C}$ and the extracted lipids were weighed gravimetrically. The collected lipids were re-dissolved in an amount of chloroform (10 times the weight of extracted lipids) and then stored at $-80{ }^{\circ} \mathrm{C}$ until further use.

\subsection{Lipid extraction from spinach chloroplast} household blender with $210 \mathrm{ml}$ of $0.3 \mathrm{M}$ aqueous sucrose solution for $1 \mathrm{~min}$ at room temperature. The slurry was filtered through three layers of cheesecloth and the chloroplasts in the filtrate were isolated by centrifugation $(1500 \mathrm{~g}, 20 \mathrm{~min})$ at $4{ }^{\circ} \mathrm{C}$. The chloroplast pellet 
was then ready for lipid extraction, following the same protocol as for the leaf, including the pre-treatment with hot isopropanol (see section 2.2). The yield of the chloroplasts was determined gravimetrically by freeze-drying until constant weight. Approximately, the amount of chloroplast obtained was $1 \mathrm{~g}$ (freeze-dried) per $100 \mathrm{~g}$ of fresh leaf.

\subsection{Lipid analysis by Thin Layer Chromatography (TLC)}

All experiments for the determination of lipid composition using TLC and gas chromatography (GC) were carried out by an external laboratory (Mylnefield Lipid Analysis at James Hutton Limited, Dundee, UK). Due to the cost involved, samples were analyzed only once.

For TLC, the major class of lipids (polar lipids and neutral lipids) were separated using 1-dimensional (1-D) glass HPTLC (high performance TLC) (Silica gel $60 \mathrm{~F}_{254}$ plates (Merck, Darmstadt, Germany)), while the polar lipids were separated using 2-dimensional (2D) glass HPTLC, as follows. A known amount of phosphatidylcholine containing heptadecanoic acid (C17:0PC) as the internal standard was added into the lipid extract to aid analysis with the 1-D TLC plate. The mixture of the lipid sample and the internal standard was spotted $(200 \mu \mathrm{l})$ onto the 1-D TLC plate and then separated in one direction using 70:30:2 (v/v/v) of isohexane/diethyl ether/formic acid solvent mix. The plate was sprayed with primuline and viewed under UV light. The lipid components were then extracted from the silica plate prior to analysis by GC.

Polar lipid separation used phosphatidyl ethanolamine containing heptadecanoic acid (C17:0PE) as the internal standard. A small amount of lipid sample was spotted near the corner and separated in two directions. A solvent mixture of $65: 25: 2.8(\mathrm{v} / \mathrm{v} / \mathrm{v})$ chloroform/methanol/water and 80:12:15:4 (v/v/v/v) chloroform/methanol/acetic acid/water was used as the solvent mixture for the first and second direction, respectively. An identical 
plate of standards was run at the same time to aid the identification of the spots on the sample plate. The polar lipid fractions, MGDG, DGDG, SQDG and trigalactosyl diacylglycerol (TGDG) were removed from the TLC plate and re-extracted from the silica. A second internal standard (henicosanoic acid, C21:0) was added to all fractions before esterification for GC analysis.

The band of TLC adsorbent containing lipids was scraped and put into a glass test tube. About $1 \mathrm{ml}$ of toluene and $2 \mathrm{ml}$ of methanolic sulfuric acid ( $1 \%$; v/v) were added into the glass test tube. The mixture was then heated to, and held at, $50{ }^{\circ} \mathrm{C}$ for $14-16 \mathrm{~h}$. After cooling, it was shaken with $2 \mathrm{ml}$ of isohexane and $5 \mathrm{ml}$ of $\mathrm{NaCl}$ solution $(5 \%$; w/v). The solvent was then transferred into a new glass test tube. The previous test tube was shaken with another $2 \mathrm{ml}$ of hexane and the two solvents were combined in the new glass test tube. The combined solvents were shaken with $3 \mathrm{ml}$ of $\mathrm{KHCO}_{3}$ solution $(2 \%$; w/v). The solvent mixture was then transferred into a new tube and $1 \mathrm{ml}$ of toluene was added before blowing off the solvents into dryness with $\mathrm{N}_{2}$ gas. After that, isohexane and BHT (butylated hydroxytoluene, antioxidant) were added to give a lipid concentration of $5 \mathrm{mg} / \mathrm{ml}$. The fatty acids methyl esters (FAMEs) were then ready to be injected into the gas chromatograph for further analysis.

\subsection{Lipid analysis by Gas chromatography $(\mathrm{GC})$}

The profile of the fatty acid methyl esters (FAMEs) was determined using GC (Agilent 6890, Agilent, USA). The fatty acids were separated using a capillary column (Cpwax $52 \mathrm{CB}, 30 \mathrm{~mm}$ x $0.25 \mathrm{~mm}$ internal diameter x $0.15 \mu \mathrm{m}$, Agilent, UK). Hydrogen was used as the carrier gas at the flow rate of $40 \mathrm{ml} / \mathrm{min}$. The column temperature was initially held at $170{ }^{\circ} \mathrm{C}$ for $3 \mathrm{~min}$. The temperature was then increased to $220{ }^{\circ} \mathrm{C}$ at $4{ }^{\circ} \mathrm{C} / \mathrm{min}$ and maintained for $10 \mathrm{~min}$. An amount of $1 \mu \mathrm{l}$ of sample was injected into a $230{ }^{\circ} \mathrm{C}$ inlet with a 
200

201

202

203

204

205

206

207

50:1 split ratio. A flame ionization detector at a temperature of $300^{\circ} \mathrm{C}$ was used. The data were processed by integrating the area under the curve and the results are reported as normalized area (\%) and $\mathrm{mg}$ fraction/g oil.

\subsection{Preparation of oil phases for oil-based suspension system} Surfactants (spinach lipids (either leaf or chloroplast), lecithin or PGPR) in sunflower oil solutions were prepared at concentrations of $0.1 \%, 0.3 \%, 0.5 \%$ and $0.7 \%$ $(\mathrm{w} / \mathrm{w})$. The sunflower oil was first purified with $4 \%(\mathrm{w} / \mathrm{w})$ magnesium silicate and stirred for $30 \mathrm{~min}$ at $600 \mathrm{rpm}$ followed by centrifugation at $1700 \mathrm{~g}$ for $25 \mathrm{~min}$ to remove the silicate. To prevent re-introduction of surface active material due to rancidification, the purified oil was stored in the dark at $4{ }^{\circ} \mathrm{C}$ for a maximum of one week. The absence of surface activity within the one week was validated by measuring interfacial tension against water to ensure that it was constant at $30 \pm 1 \mathrm{mN} / \mathrm{m}$.

The addition of spinach lipid to the purified oil followed a procedure of mixing in chloroform dissolved extract (roughly $1 \mathrm{~g}$ extract depending on extract yield in the 10 volumes of chloroform, as stated in section 2.2) with purified oil $(50 \mathrm{~g})$ in a round bottom flask and mixed by swirling for at least $1 \mathrm{~min}$. This was followed by allowing the chloroform to evaporate at $40^{\circ} \mathrm{C}$. Complete evaporation of the chloroform was checked by mass balance. By diluting with purified oil, the desired spinach lipid concentrations of $0.1 \%, 0.3 \%, 0.5 \%$ and $0.7 \%(\mathrm{w} / \mathrm{w})$ were obtained.

Purified oil containing lecithin and PGPR at the same concentrations were prepared by mixing the required amount of either lecithin or PGPR with purified oil (up to $100 \mathrm{~g}$ ) in a glass beaker by stirring for $24 \mathrm{~h}$ on a magnetic stirrer at $600 \mathrm{rpm}$ and room temperature.
2.7.
Dynamic interfacial tension 
The interfacial tension at the water/oil interface was measured as a function of time

with a Drop Shape Tensiometer (PAT-1, Sinterface, Berlin, Germany) for surfactant concentrations of $0 \%, 0.001 \%$ and $0.005 \%(\mathrm{w} / \mathrm{w})$ in the oil. The highest concentration was limited to $0.005 \%(\mathrm{w} / \mathrm{w})$ due to the deep green color of the spinach lipid extract which interfered with the measurement principle (reliance on translucency of non-drop forming fluid). The (lightly green colored) oil phase was added to a cubic glass cuvette and a drop of water, with a cross sectional projection area of $30 \mathrm{~mm}^{2}$, was suspended into the oil sample from the tip of a straight capillary of $2 \mathrm{~mm}$ outer diameter. The drop was formed in less than one second and its shape was monitored for $900 \mathrm{~s}$ by a video camera coupled to a computer.

The measurement temperature was $20^{\circ} \mathrm{C}$. The values reported in the results section represent an average of three independent measurements.

2.8. Particle size distribution of icing sugar

The icing sugar used in this study was pre-dried at $60{ }^{\circ} \mathrm{C}$ for $24 \mathrm{~h}$ under a pressure of 800 mbar using a vacuum oven (Gallenkamp, Fistreem International, Loughborough, UK).

240 The particle size of the icing sugar was analyzed using laser diffraction equipment (Beckman

241 Coulter LS13320, Meritics, Wycombe, UK), fitted with a dry powder module (Beckman

242 Tornado Dry Powder System, Meritics, UK). The distribution was tri-modal and therefore 243 separated into three populations, using the equipment's software. The size boundaries with 244 the respective volume based fraction of the total distribution, as well as the characteristic 245 particle sizes are reported in Table 1.

\section{Table 1}

247 Characteristic size distribution values for the three particle populations of the icing sugar 248 sample used in the sugar/oil suspension systems. The percentage volume differential shows 249 the total amount (in percent) of particles in the particular group of size particle. Reported are 
the volume based diameter $\mathrm{d}_{4,3}$ describing the common mean diameter over the volume distribution for a monodispersed sample and the volume based characteristic particle sizes for which $10 \%, 50 \%$ and $90 \%$ of the particles were smaller than the size boundary.

\begin{tabular}{llll}
\hline Size boundary & $0.38-1.83 \mu \mathrm{m}$ & $1.83-76.43 \mu \mathrm{m}$ & $76.43-194.20 \mu \mathrm{m}$ \\
\hline Volume $(\%)$ & $6.43 \pm 0.22$ & $80.47 \pm 0.06$ & $13.10 \pm 0.30$ \\
$d_{4,3}(\mu \mathrm{m})$ & $0.97 \pm 0.01$ & $26.05 \pm 0.16$ & $107.33 \pm 3.12$ \\
$d_{10,3}(\mu \mathrm{m})$ & $0.53 \pm 0.01$ & $5.59 \pm 0.07$ & $81.70 \pm 0.40$ \\
$d_{50,3}(\mu \mathrm{m})$ & $0.91 \pm 0.01$ & $21.83 \pm 0.25$ & $104.43 \pm 2.87$ \\
$d_{90,3}(\mu \mathrm{m})$ & $1.55 \pm 0.01$ & $54.20 \pm 0.18$ & $137.07 \pm 5.34$
\end{tabular}

253

254

\subsection{Density of icing sugar}

The density of the icing sugar needed to be known to adjust the phase volume of the suspensions. It was determined at room temperature using the volume displacement method based on sunflower oil with the density of $0.92 \pm 0.02 \mathrm{~g} / \mathrm{cm}^{3}$, previously determined with a density meter (Anton Paar, Germany), as follows. An equal weight of sugar and oil were mixed together using an impeller stirrer (1000 rpm, $60 \mathrm{~min})$ until well dispersed. Based on the weight of a known volume of the dispersion the density of the icing sugar was computed as $1.55 \pm 0.04 \mathrm{~g} / \mathrm{cm}^{3}$. This was comparable with a published value of $1.58 \mathrm{~g} / \mathrm{cm}^{3}$ (Arnold et al., 2013).

\subsection{Preparation of sugar/oil suspension} The effect of the lipid extracts as a rheology modifier in comparison to the commercial reference surfactants was tested on sugar/oil suspensions with sugar volume fractions of $0.28,0.33$ and 0.37 . The suspensions were prepared by dispersing the appropriate 
amount of sugar into pre-prepared oil phase, containing surfactant at the desired concentration, with an impeller stirrer (IKA Werke, Staufen, D) operated at $1000 \mathrm{rpm}$ for 60 min. To prevent sedimentation of the sugar, the suspensions were then continuously mixed at gentle mixing condition for $24 \mathrm{~h}$ using an end-over-end mixer (Reax 2, Heidolph, Schwabach, D) until rheological measurement was performed. The selection of the sugar volume fractions and the design of the suspension preparation protocol was based on published literature (Arnold et al., 2013) that also guided the selection of the rheology protocol applied here (see section 2.11). These authors formulated their sugar in soybean oil suspension at the sugar mass fraction of 0.45 , which equates to the sugar volume fraction of 0.33 in our system. Here, $0.4(0.28)$ and $0.5(0.37)$ as a slightly lower and higher mass (volume) fraction of sugar respectively was included in the experimental design. Therefore, in terms of fat content, the suspensions assessed in this study ranged from 50 to $60 \%(\mathrm{w} / \mathrm{w})$. This is higher than in commercial chocolate formulations, 29 to $40 \%(\mathrm{w} / \mathrm{w})$ as aforenoted, rendering the system less viscous. With a $\mathrm{D}_{90}$ of $137 \mu \mathrm{m}$, see Table 1, the sugar particles were significantly larger than the $\mathrm{D}_{90}$ of around $30-40 \mu \mathrm{m}$ of commercial formulations (Afoakwa, Paterson \& Fowler, 2008) and, together with the larger fat content, the lower energy input provided by the overhead mixing set-up compared to industrial chocolate manufacture sufficed to ensure breaking up of sugar aggregates and homogeneous coating of the sugar particles. It is also worth noting that here, in difference to commercial processing, all of the surfactant was present at the beginning of the mixing process.

\subsection{Suspension rheology}

The rheological properties of the sugar/oil suspensions were evaluated by acquiring shear viscosity curves on a rotational shear rheometer (MCR 301, Anton Paar, Graz, A) fitted 
293

294

295

296

297

298

299

300

301

302

303

304

305

306

307

with a concentric cylinder geometry (bob diameter of $27 \mathrm{~mm}$, cup diameter of $29 \mathrm{~mm}$, bob length of 40 mm; CC27, Anton Paar, Graz, A). Published protocol (Arnold et al., 2013) was followed and slightly modified by starting the measurement with a pre-shear at $10 \mathrm{~s}^{-1}$ for $50 \mathrm{~s}$ to improve the reproducibility of the data. Real measurement started by increasing shear rate from $0.01 \mathrm{~s}^{-1}$ to $1000 \mathrm{~s}^{-1}$ in a logarithmic ramp within $990 \mathrm{~s}$. After stopping the shear for 120 $\mathrm{s}$, the shear rate was decreased from $1000 \mathrm{~s}^{-1}$ to $0.01 \mathrm{~s}^{-1}$ (logarithmic ramp, $990 \mathrm{~s}$ ). Fifty-one data points were taken on each logarithmic ramp with the measurement time logarithmically decreasing from $100 \mathrm{~s}$ at $0.01 \mathrm{~s}^{-1}$ to $0.5 \mathrm{~s}$ at $1000 \mathrm{~s}^{-1}$, and then increasing again to $100 \mathrm{~s}$ at $0.01 \mathrm{~s}^{-1}$ for the decreasing shear rate ramp. The measurement temperature was $22{ }^{\circ} \mathrm{C}$ as in the published method (Arnold et al., 2013) and results are presented as relative viscosity (the ratio of the measured viscosity to the viscosity of the continuous phase). The addition of any of the surfactants did not affect the apparent viscosity of the sunflower oil and it remained Newtonian. The average apparent viscosity of the oil phases used in this study was $0.060 \pm$ 0.002 Pa.s. Referring to the viscosity curves obtained, the apparent viscosity and yield stress are reported as the apparent viscosity at $40 \mathrm{~s}^{-1}$ and the shear stress at $5 \mathrm{~s}^{-1}$ of the increasing shear ramp, respectively.

\subsection{Statistical analysis}

Spinach lipid extraction was carried out in duplicate (two different batches) and each batch was utilized to prepare one set of oil-based suspension phases (SPLIP and CH.SPLIP) at the required concentration. Lecithin and PGPR based oil phases were also prepared independently in duplicate at the required concentrations. Each suspensions prepared from each oil phase was then analyzed in duplicate. A third batch was prepared if unreliable data were obtained. All data are presented as mean values \pm standard deviations of $n=4$. Mean comparison was carried out using one-way ANOVA. Significant differences between 
samples were analysed using Tukey HSD (Honestly Significant Different) multiple comparisons test at $95 \%$ confidence level. The software used was IBM SPSS Statistics 22.

\section{Results and discussion}

\subsection{Yield of lipid extracts}

$14.9( \pm 4.5) \mathrm{g} / 100 \mathrm{~g}$ dried spinach leaf and $24.0( \pm 4.6) \mathrm{g} / 100 \mathrm{~g}$ dried chloroplast, respectively. The higher yield from the chloroplast was expected as the lipids in green plant leaf tissue are mostly concentrated in the chloroplast (Nishimura, Graham, \& Akazawa, 1976). The yield from the leaf was comparable to values reported by Fricker, Duben, Heintze, Panlas, and Zohm (1975) and Yunoki et al. (2009). However, a result reported by Menke (1938) was about $10 \%$ higher than the data reported in this study. As the amount of isolated chloroplasts obtained was about $1 \mathrm{~g}$ (dry weight) per $100 \mathrm{~g}$ of fresh spinach leaves, $100 \mathrm{~g}$ fresh spinach leaves would yield $0.24( \pm 0.05) \mathrm{g}$ lipids from the isolated chloroplasts. On the other hand, directly extracted lipid obtained from the whole fresh leaves, thereby omitting the chloroplast isolation step, was $0.89( \pm 0.27) \mathrm{g}$ per $100 \mathrm{~g}$ of fresh spinach leaves rendering the direct use of leaf commercially more interesting.

\subsection{Lipid classes}

The lipid classes in the two spinach extracts were initially identified by separation using the method of 1D TLC, see Fig. 1 for the chromatogram. Lipids detected for both extracts were sterol ester (SE), triacylglycerols (TAG), free fatty acids (FFA), free sterol

340 (FS), diacylglycerols (DAG), monoacylglycerols (MAG) and polar lipids (PL). The polar

341 lipid spot remained at the origin of the plate showing that it was strongly absorbed to the 342 stationary phase. Non-polar lipids eluted and appeared at the end of the chromatogram. Polar 
343 lipids were reported to be in abundance in spinach (Dörmann, 2013), explaining their more 344 intense spots compared to the spots of the other lipid classes.

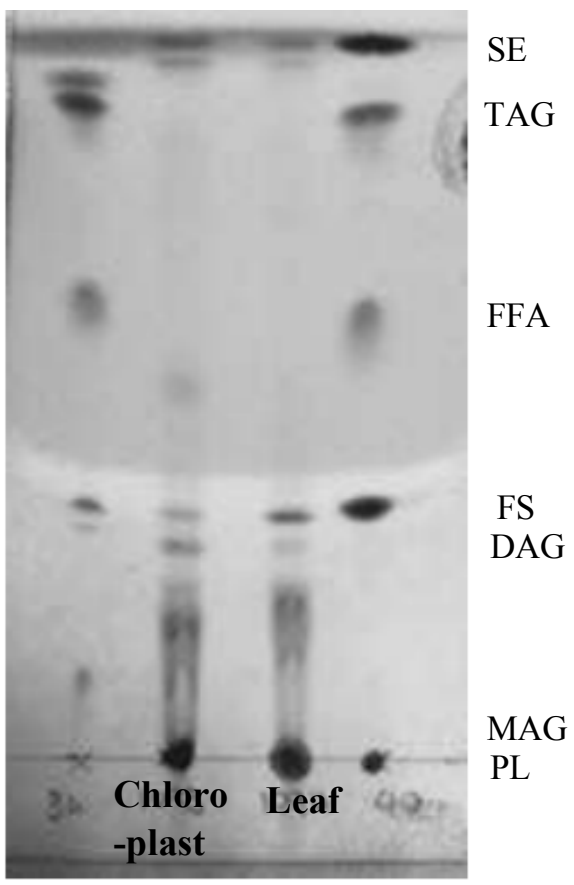

346 Fig. 1. Separation of lipid from spinach leaf and spinach chloroplast. Abbreviation denote:

$347 \mathrm{SE}=$ sterol ester, $\mathrm{TAG}=$ triacylglycerols, $\mathrm{FFA}=$ free fatty acids, $\mathrm{FS}=$ free sterol, $\mathrm{DAG}=$ 348 diacylglycerols, $\mathrm{MAG}=$ monoacylglycerols, $\mathrm{PL}=$ polar lipids.

Due to the complexity of the polar lipid fractions, these were further separated by

2D TLC, see Fig. 2. Both lipid extracts contained similar classes of polar lipid but the

352 intensity of the spots was higher for the chloroplast lipids. The polar lipids included the two major galactosyl diacylglycerides (MGDG and DGDG) and sulfolipid (SQDG). The spot near

354 the origin was suspected to be TGDG but no standard was available to confirm. The major 355 phospholipids in spinach were also spotted, such as PC and PG. 

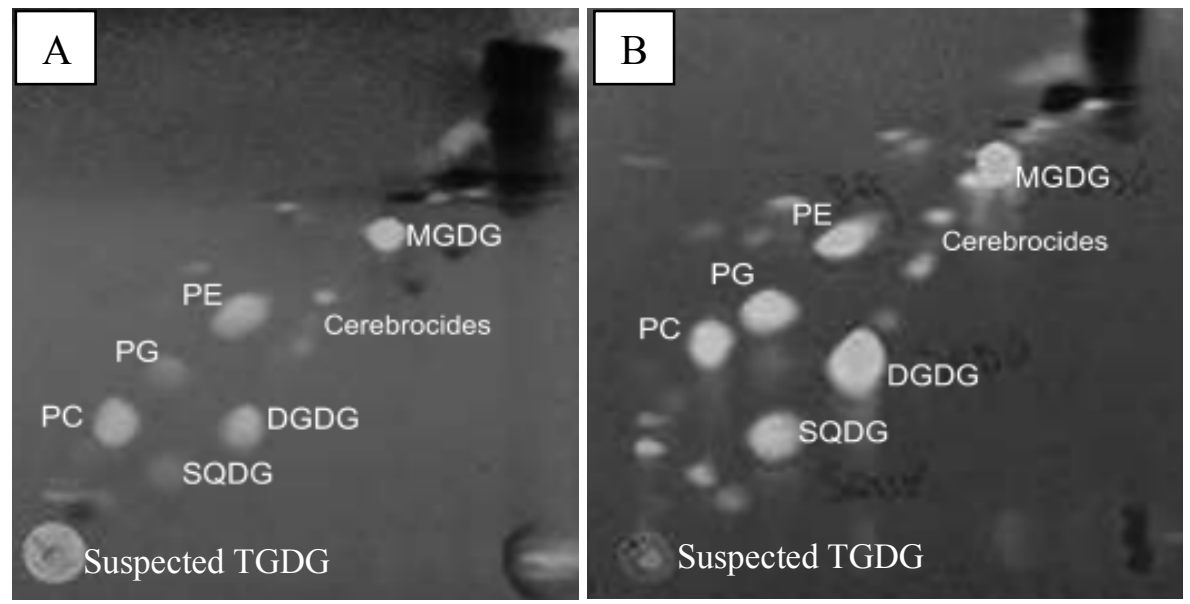

357 Fig. 2. Polar lipids separated on 2D TLC plate. (A): from spinach leaf; (B) from spinach chloroplast. Abbreviation denote: $\mathrm{MGDG}=$ monogalactosyl diacylglycerol, $\mathrm{DGDG}=$ digalactosyl diacylglycerol, SQDG = sulfoquinovosyl diacylglycerol, TGDG = trigalactosyl diacylglycerol, $\mathrm{PC}=$ phosphatidyl choline, $\mathrm{PE}=$ phosphatidyl ethanolamine, $\mathrm{PG}=$ 361 phosphatidylglycerol.

The concentration of each polar lipid class was determined by GC and the results are shown in Table 2. The chloroplast-rich fraction was highly concentrated in glycolipids with its amount double compared to that of phospholipids, while the lipid extracted directly from the leaf tissue possessed an equal amount of phospholipids and glycolipids. The results also confirmed the abundance of MGDG and DGDG in the spinach leaf and chloroplast. The ratio of phospholipids to glycolipids was comparable to that reported by Dörmann and

369 Benning (2002), where approximately $70 \%$ glycolipids content was detected. The phospholipids ratio was slightly higher in leaf than in the chloroplast and this was similar to the results reported by Wintermans (1960). Besides, not taking TGDG into account, the

372 results obtained for spinach leaf lipid in this study was also comparable to those reported by

373 Yunoki et al. (2009).

\section{$374 \quad$ Table 2}

375 Polar lipids compositions of spinach leaf and chloroplasts (mg/ g lipids) 


\begin{tabular}{|c|c|c|c|c|c|c|c|c|}
\hline & \multirow{2}{*}{$\begin{array}{l}\text { Total } \\
\text { phospho- } \\
\text { lipids (PhL) }\end{array}$} & \multirow{2}{*}{$\begin{array}{l}\text { Total } \\
\text { glycolipids } \\
\text { (GL) }\end{array}$} & \multirow{2}{*}{$\begin{array}{l}\text { Ratio } \\
\text { PhL:GL }\end{array}$} & \multicolumn{4}{|c|}{ Individual glycolipids } & \multirow{2}{*}{$\begin{array}{l}\text { Ratio } \\
\text { M:D:T:S }\end{array}$} \\
\hline & & & & $\begin{array}{l}\text { MGDG } \\
\text { (M) }\end{array}$ & $\begin{array}{l}\text { DGDG } \\
\text { (D) }\end{array}$ & $\begin{array}{l}\text { TGDG } \\
(\mathrm{T})\end{array}$ & $\begin{array}{l}\text { SQDG } \\
\text { (S) }\end{array}$ & \\
\hline Chloroplast & 181.8 & 418.9 & $30: 70$ & 202.4 & 124.2 & 53.2 & 39.1 & $48: 30: 13: 9$ \\
\hline Leaf & 201.6 & 240.7 & $46: 54$ & 113.7 & 79.6 & 24.8 & 22.6 & $47: 33: 10: 9$ \\
\hline
\end{tabular}

376

377

378

379

380

381

\subsection{Fatty acids composition}

The fatty acids composition of the polar lipids from spinach chloroplast $(\mathrm{CH})$ and

leaf (L) are tabulated in Table 3. Generally, the polar lipids were highly concentrated in the two trienoic acids: hexadecatrienoic and $\alpha$-linolenic acid. The amount of $\alpha$-linolenic acid was particularly high, accounting for $71 \%$ and $58 \%$ of the total lipids in chloroplast and leaf, respectively. MGDG and DGDG were made up of more than $75 \% \alpha$ - linolenic acid, similar to what has previously been reported (Gounaris, Mannock, et al., 1983; Melo, Tavares, Morais, Barroso, \& Pais, 1995). The high content of polyunsaturated fatty acids in chloroplast lipid is very important as to maintain their biological function at low temperatures (Andersson \& Dörmann, 2009). The amount of hexadecatrienoic acid in MGDG was higher than in other polar lipids, comparable to what has previously been reported for solanaceous leaf (Whitaker, 1986). The presence of hexadecatrienoic (16:3) classifies spinach as a 16:3 plant, as this fatty acid is only present in certain plants (Andersson \& Dörmann, 2009). SQDG had an equal amount of 16:0 and 18:3 fatty acids as previously reported (Siebertz, Heinz, Linscheid, Joyard, \& Douce, 1979).

\section{Table 3}

Fatty acid composition of polar lipids from spinach leaf and chloroplasts ( $\%$ total lipids)

\begin{tabular}{llllllllllll}
\hline & \multicolumn{2}{l}{ Total Polar } & MGDG & DGDG & TGDG & & \multicolumn{2}{c}{ SQDG } \\
Fatty acids & \multicolumn{2}{l}{ Lipids } & & & & & & & & & \\
& & & & & & & & & & & \\
& CH & L & CH & L & CH & L & CH & L & CH & L \\
& & & & & & & & & & \\
\hline $14: 0$ (myristic) & 0.1 & 0.1 & - & 0.1 & 0.1 & 0.2 & 4.2 & 2.0 & 0.5 & 0.7 \\
$15: 0$ (pentadecylic) & - & 0.1 & - & - & - & - & - & - & - & 0.4 \\
\hline
\end{tabular}




\begin{tabular}{|c|c|c|c|c|c|c|c|c|c|c|}
\hline 16:0 (palmitic) & 6.8 & 12.5 & 0.7 & 0.6 & 4.3 & 5.8 & 24.1 & 15.0 & 41.6 & 45.6 \\
\hline 16:1 (palmitoleic) & 3.8 & 3.0 & 0.3 & 0.1 & 1.1 & 0.2 & 25.2 & 8.3 & 3.4 & 0.6 \\
\hline 16:2 (polyenoic) & 0.1 & 0.1 & - & 0.1 & 0.2 & 0.2 & 6.7 & 2.0 & 0.7 & 0.7 \\
\hline 17:0 (margaric) & - & - & - & - & 0.1 & 0.1 & - & - & - & - \\
\hline $\begin{array}{l}16: 3(n-3) \\
\text { (hexadecatrienoic) }\end{array}$ & 11.1 & 0.8 & 18.6 & 20.6 & 3.3 & 3.3 & - & - & 0.6 & 1.0 \\
\hline 18:0 (stearic) & 0.4 & 0.6 & 0.3 & 0.2 & 0.8 & 1.1 & 13.9 & 16.3 & 2.5 & 2.3 \\
\hline 18:1 (n-9) (elaidic) & 1.0 & 2.7 & - & 0.1 & 0.4 & 0.9 & 2.9 & 4.4 & 2.9 & 0.6 \\
\hline $18: 1(\mathrm{n}-7)$ (vaccenic) & 0.7 & 1.0 & 0.4 & 0.4 & 1.6 & 1.4 & - & - & 0.5 & 0.6 \\
\hline 18:2 (n-6) (linoleic) & 4.6 & 11.3 & 0.9 & 0.9 & 1.1 & 2.0 & 3.3 & 2.1 & 5.3 & 3.2 \\
\hline $\begin{array}{l}18: 3(n-3)(\alpha- \\
\text { linolenic) }\end{array}$ & 70.7 & 58.2 & 78.7 & 76.3 & 86.1 & 83.2 & - & 3.1 & 40.3 & 42.4 \\
\hline 20:0 (arachidic) & 0.1 & 0.4 & - & 0.1 & 0.2 & 0.2 & 4.4 & 21.3 & 0.5 & 0.5 \\
\hline 20:1 (gondoic) & 0.1 & 0.4 & - & - & - & - & - & - & - & - \\
\hline $20: 3(n-3)($ mead $)$ & 0.2 & 0.1 & - & 0.1 & 0.3 & 0.4 & - & - & - & - \\
\hline 22:0 (behenic) & 0.1 & 0.4 & - & 0.1 & 0.2 & 0.2 & 4.3 & 20.9 & 0.5 & 0.5 \\
\hline 22:1 (erucic) & - & - & - & 0.2 & - & - & - & - & - & - \\
\hline 24:0 (lignoceric) & 0.2 & 0.9 & - & 0.2 & 0.3 & 0.8 & 11.1 & 4.6 & 0.6 & 1.1 \\
\hline
\end{tabular}

394

3.4. Interfacial tension at oil/water interface

The surface activity of the lipid extracts was assessed by measuring interfacial

tension at the oil/water interface at $20^{\circ} \mathrm{C}$ and the results are reported in Fig. 3 alongside reference data for $0 \%$ added surfactant in the oil phase. As expected, the reference data showed no time dependency, while the interfacial tension at the surfactant-laden interfaces decreased initially followed by asymptotically approaching a constant value at times longer than $600 \mathrm{~s}$ after generation of the interface. The only exception is the interfacial pair of 0.005 $\%$ SPLIP in oil/water for which equilibrium was approached later, around $900 \mathrm{~s}$ after generation of the interface. Attainment of equilibrium was taken as a change of less than 1 $\mathrm{mN} / \mathrm{m}$ in interfacial tension over at least $100 \mathrm{~s}$ measurement time. As expected, the data tended to lower values at higher surfactant concentration. Equilibrium interfacial tension values are reported in Table 4; the value for the pure oil/water interface was calculated by averaging the data of the full $900 \mathrm{~s}$ of measurement and the other data were obtained by averaging the value at $900 \mathrm{~s}$ for three replicate measurements. The interfacial tension at the 
410 (Gaonkar \& Borwankar, 1991; Gülseren \& Corredig, 2012). This value was statistically

411 significantly lower in the presence of $0.005 \%(\mathrm{w} / \mathrm{w})$ of either spinach lipid $(\mathrm{p}<0.05)$. No

412 further significant differences were observed as the concentration of surfactant was kept very

413 low to allow sufficient optical contrast between the water droplet and the deep green oil

414 phase containing spinach lipid. Nonetheless, the interfacial tension data gave evidence for the

415 surface activity of the spinach lipid extracts and thus one would expect these to be

416 functionally active as rheology modifiers in sugar/oil suspensions.

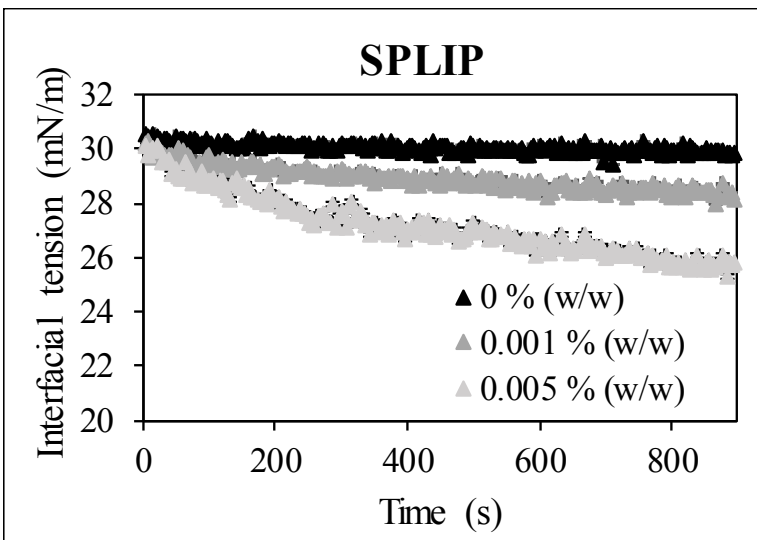

PGPR

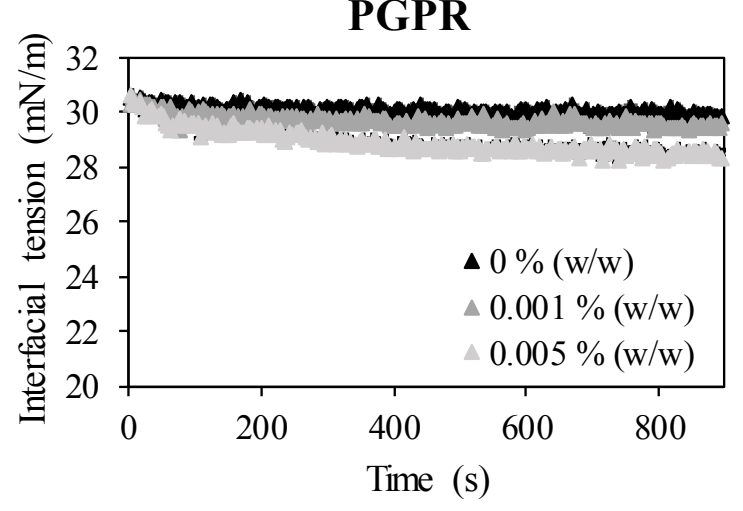

CH.SPLIP

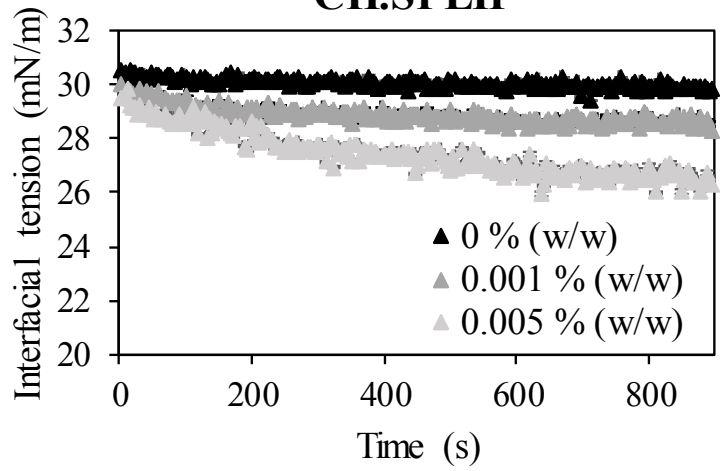

Lecithin

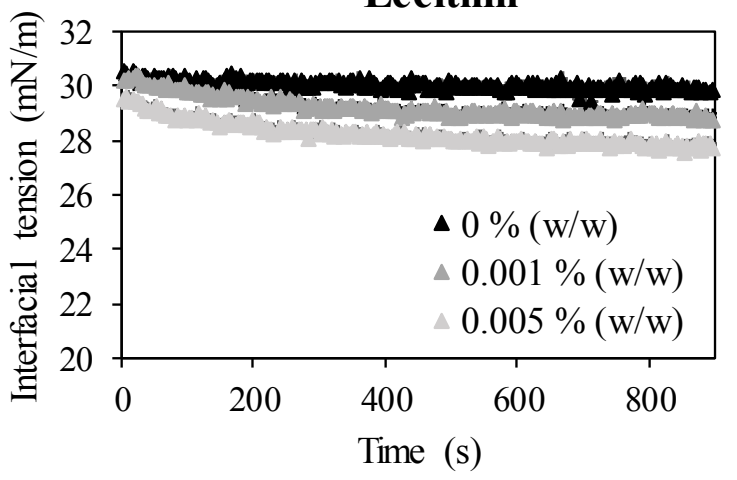

418 Fig. 3. Surface tension at the water-oil interface of added surfactant either with leaf lipid,

419 chloroplast lipid, lecithin or PGPR. Data plotted as means \pm 1 for standard deviation for $\mathrm{n}=3$.

\section{$421 \quad$ Table 4}

422 Interfacial tension at the oil/water interface $\left(20^{\circ} \mathrm{C}\right)$ in presence of spinach lipid extract from

423 leaf or chloroplast, PGPR or lecithin (mean value recorded at $900 \mathrm{~s}$ ). Different subscript

424 letters indicate statistically significant difference in the data $(\mathrm{p}<0.05)$. 


\begin{tabular}{|c|c|}
\hline Oil sample & $\begin{array}{l}\text { Interfacial tension } \\
\left(\mathrm{mN} \cdot \mathrm{m}^{-1}\right)\end{array}$ \\
\hline Control & $30.0 \pm 0.1^{\mathrm{a}}$ \\
\hline SPLIP $0.001 \%$ & $28.4 \pm 0.4^{\mathrm{abc}}$ \\
\hline SPLIP $0.005 \%$ & $25.8 \pm 1.0^{\mathrm{c}}$ \\
\hline CH.SPLIP $0.001 \%$ & $28.6 \pm 0.9^{\mathrm{abc}}$ \\
\hline CH.SPLIP $0.005 \%$ & $26.6 \pm 1.2^{\mathrm{bc}}$ \\
\hline PGPR $0.001 \%$ & $29.5 \pm 1.5^{\mathrm{ab}}$ \\
\hline PGPR $0.005 \%$ & $28.7 \pm 1.1^{\mathrm{abc}}$ \\
\hline LEC $0.001 \%$ & $28.9 \pm 1.1^{\mathrm{ab}}$ \\
\hline LEC $0.005 \%$ & $27.8 \pm 1.5^{\mathrm{abc}}$ \\
\hline
\end{tabular}

426 3.5. The effect of spinach lipids, PGPR and lecithin on the viscosity profile of sugar/oil suspensions

The rheology modifying properties of the two natural spinach lipid extracts were evaluated by comparing the shear rheological behavior of sugar/oil suspensions to those

430 prepared with PGPR and lecithin. The results are reported on the basis of the viscosity 431 profiles as well as the IOC chocolate rheology parameters recommended for use in industry 432 (International Office of Cocoa, 2000), and then discussed by suggesting a mechanistic model 433 for the rheology modifying properties of the spinach lipids. The apparent viscosity data acquired by analyzing the sugar/oil suspensions with a sugar volume fraction of $0.28,0.33$ or 0.37 are presented in Fig. $4-6$ as relative viscosity. At different sugar volume fraction, the surfactant systems were applied between $0-0.7 \%(\mathrm{w} / \mathrm{w})$. Data are shown as a function of shear stress to evaluate whether the natural lipid extracts would assume the functionality of PGPR in oil-based suspensions, applied to modify rheology at low shear region. sugar/oil suspensions showed a shear thinning behavior and a transition to a Newtonian 441 plateau at high shear stress. Referring to the increasing shear ramp data, and in accordance 442 with literature (Taylor, Van Damme, Johns, Routh, \& Wilson, 2009), the minimum stress required for the onset of flow is termed critical stress in the following discussion - to 
444 distinguish from the yield stress definition as put forward by the IOC. However, the

445 increasing shear ramp data of a number of samples revealed initial elastic behavior prior to

446 transitioning to liquid-like behavior signified by the onset of the smooth sharply decreasing

447 apparent viscosity data trace. Where solid-like flow regions were observed, they are

448 highlighted in Fig. 4(B), 5(B) and 6(B). The final stress value of this region, corresponding to

449 the first stress value signifying liquid-like flow behavior, was taken as the critical stress.

450 Otherwise, the first stress value recorded was taken as the critical stress. However, some

451 initial data was clearly influenced by the fact that a pre-shear was applied ( $10 \mathrm{~s}^{-1}$ for $\left.50 \mathrm{~s}\right)$, as

452 the data recorded at the initial shear stress values were lower than the data at higher shear. In

453 this instance, the first data point showing a decrease in apparent viscosity after this pre-shear

454 affected area was taken as the critical stress value, such as for the highest volume fraction

455 suspension containing $0.7 \%(\mathrm{w} / \mathrm{w})$ PGPR (Fig. 6).

At a sugar volume fraction of 0.28 , the critical stress values ranged from 0.04 to 0.1

$457 \mathrm{~Pa}$ at $0.1 \%$ addition, in the order of lecithin (0.04 Pa), SPLIP (0.04 Pa), CH.SPLIP (0.05 Pa)

458 and PGPR $(0.1 \mathrm{~Pa})$. The data were comparable to each other at concentration more than 0.3

$459 \%$, except that lecithin had an increased critical stress value, approaching $0.1 \mathrm{~Pa}$. There was

460 also an increasing trend of apparent viscosity when the lecithin concentration was increased

461 from $0.1 \%$ to $0.7 \%$. At a surfactant addition of $0.5 \%$ and $0.7 \%$, PGPR imparted a

462 significant reduction in the critical stress and apparent viscosity, with values close to $0.05 \mathrm{~Pa}$

463 in the shear thinning region and approaching a Newtonian plateau. The value recorded for

464 SPLIP and CH.SPLIP remained below $0.1 \mathrm{~Pa}$ while the value recorded for lecithin continued 465 to increase passing $0.1 \mathrm{~Pa}$. 

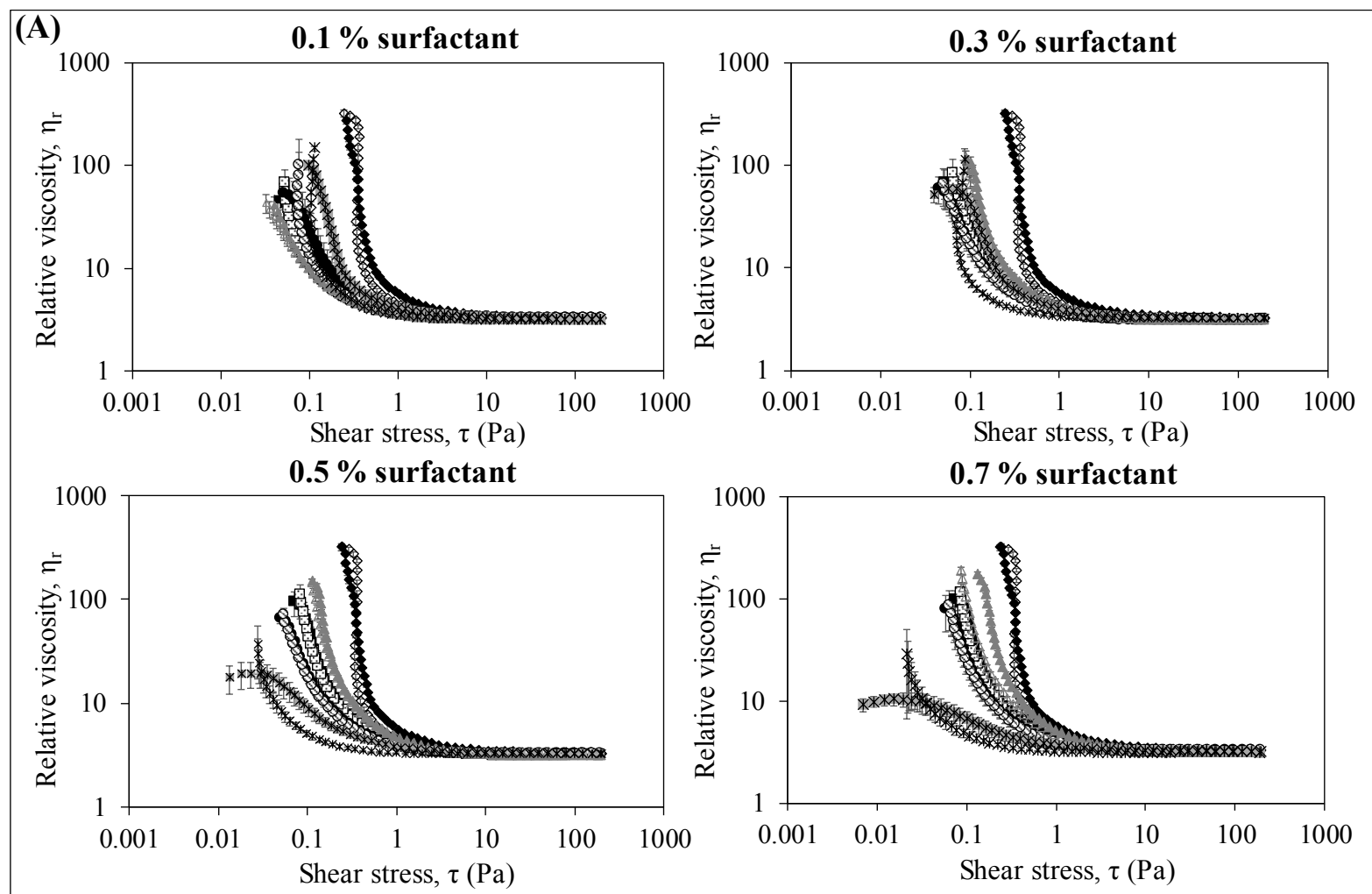

- CONTROL UP $\diamond$ CONTROL DOWN • SPLIP UP $\square$ SPLIP DOWN

- CH.SPLIP UP
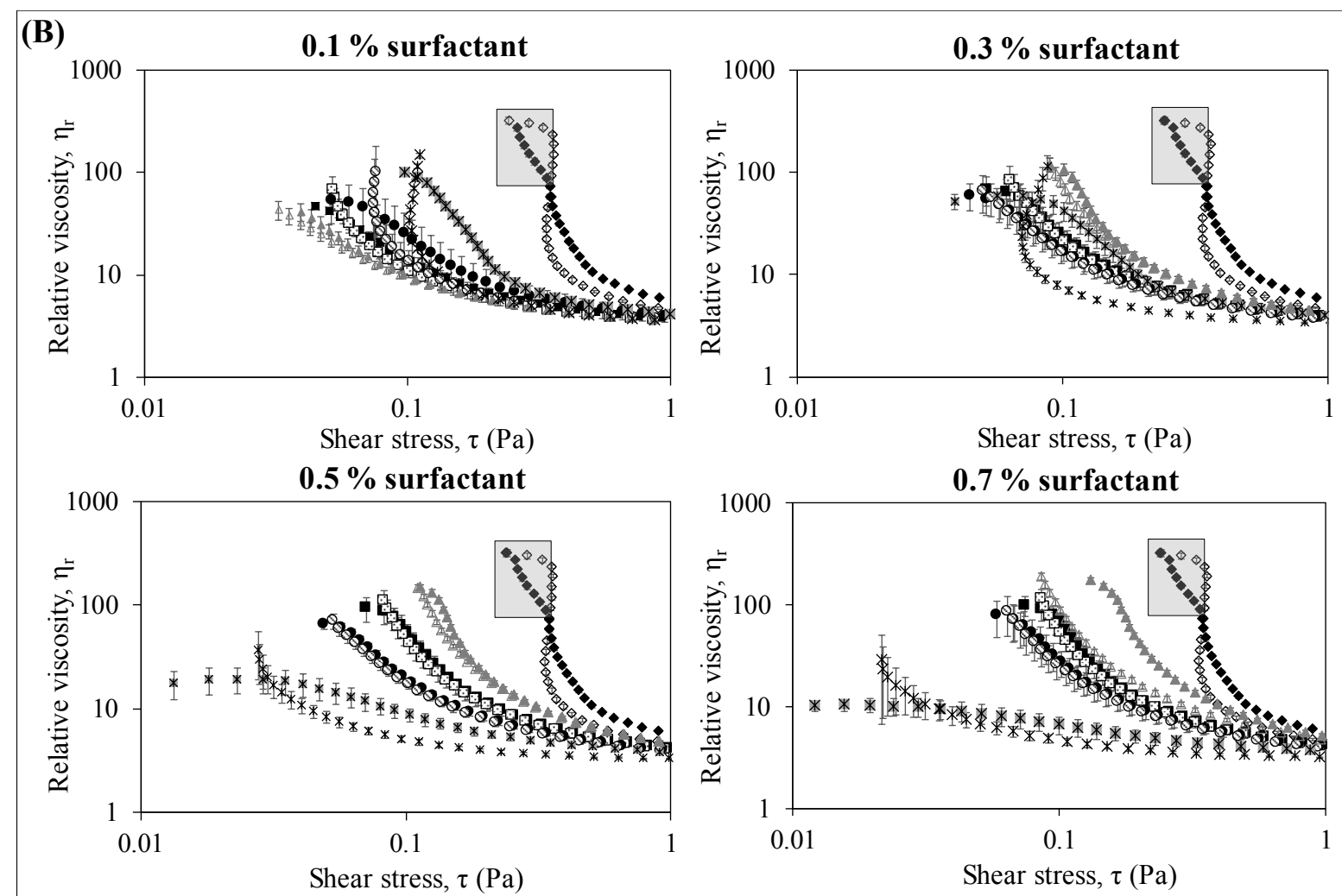

- CONTROL UP $\quad$ CONTROL DOWN - SPLIP UP

๒ SPLIP DOWN $\bullet$ CH.SPLIP UP

* PGPR UP

* PGPR DOWN 
468 Fig. 4. (A) Relative viscosity curves of sugar/oil suspensions at sugar volume fraction of 0.28

469 as affected by the concentration of surfactant (mean $\pm 1.0, n=4)$. (B) Low shear region data to

470 aid yield stress discussion. Data acquired during shear rate increase and decrease respectively

471 are labeled "UP" and "DOWN". The greyed highlighted areas signify the transition from

472 solid-like to liquid-like behavior.

473
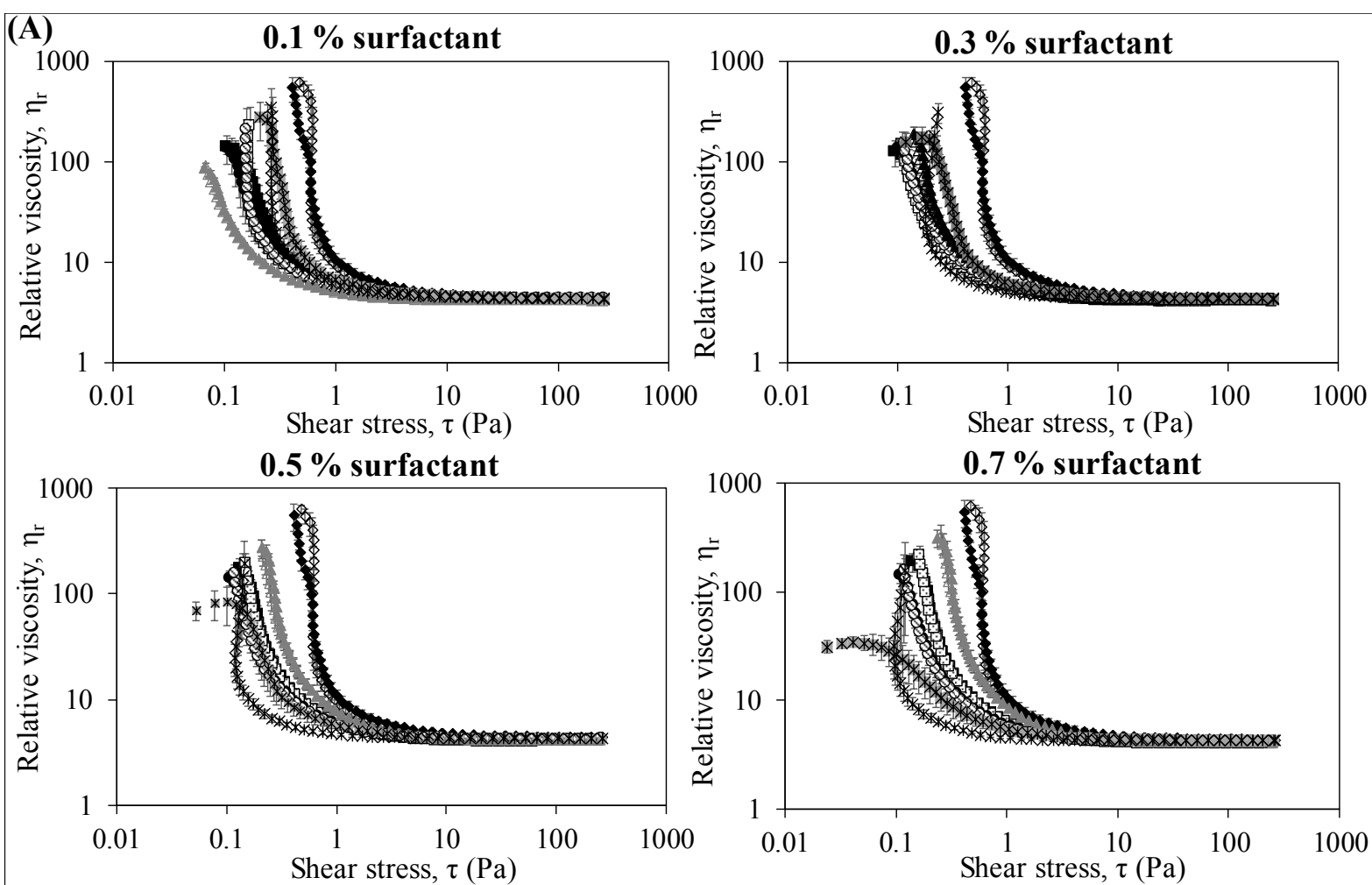


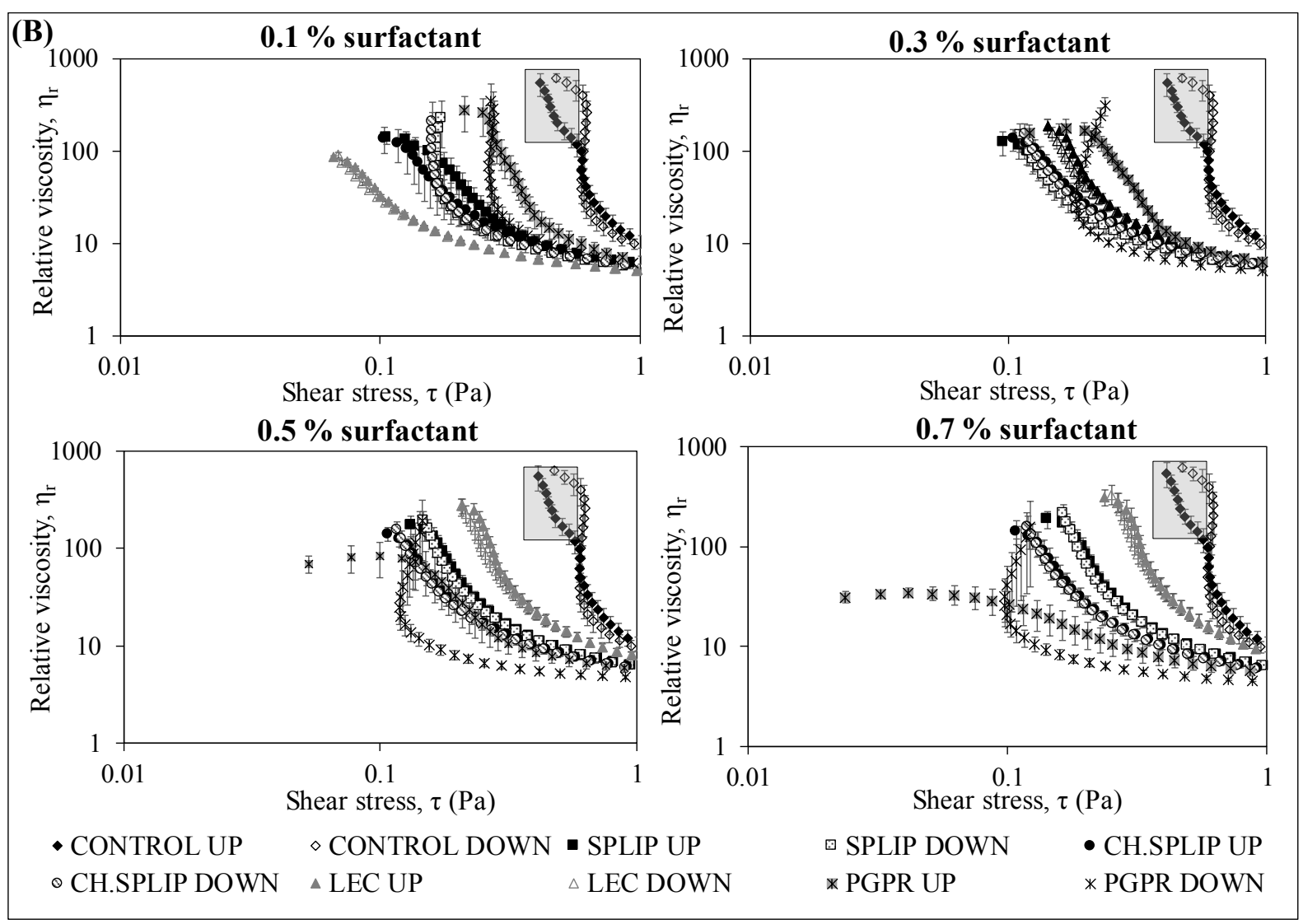

476 Fig. 5. (A) Relative viscosity curves of sugar/oil suspensions at sugar volume fraction of 0.33

477 as affected by the concentration of surfactant (mean $\pm 1.0, n=4)$. (B) Low shear region data to

478 aid yield stress discussion. Data acquired during shear rate increase and decrease respectively

479 are labeled "UP" and "DOWN". The greyed highlighted areas signify the transition from

480 solid-like to liquid-like behavior. 

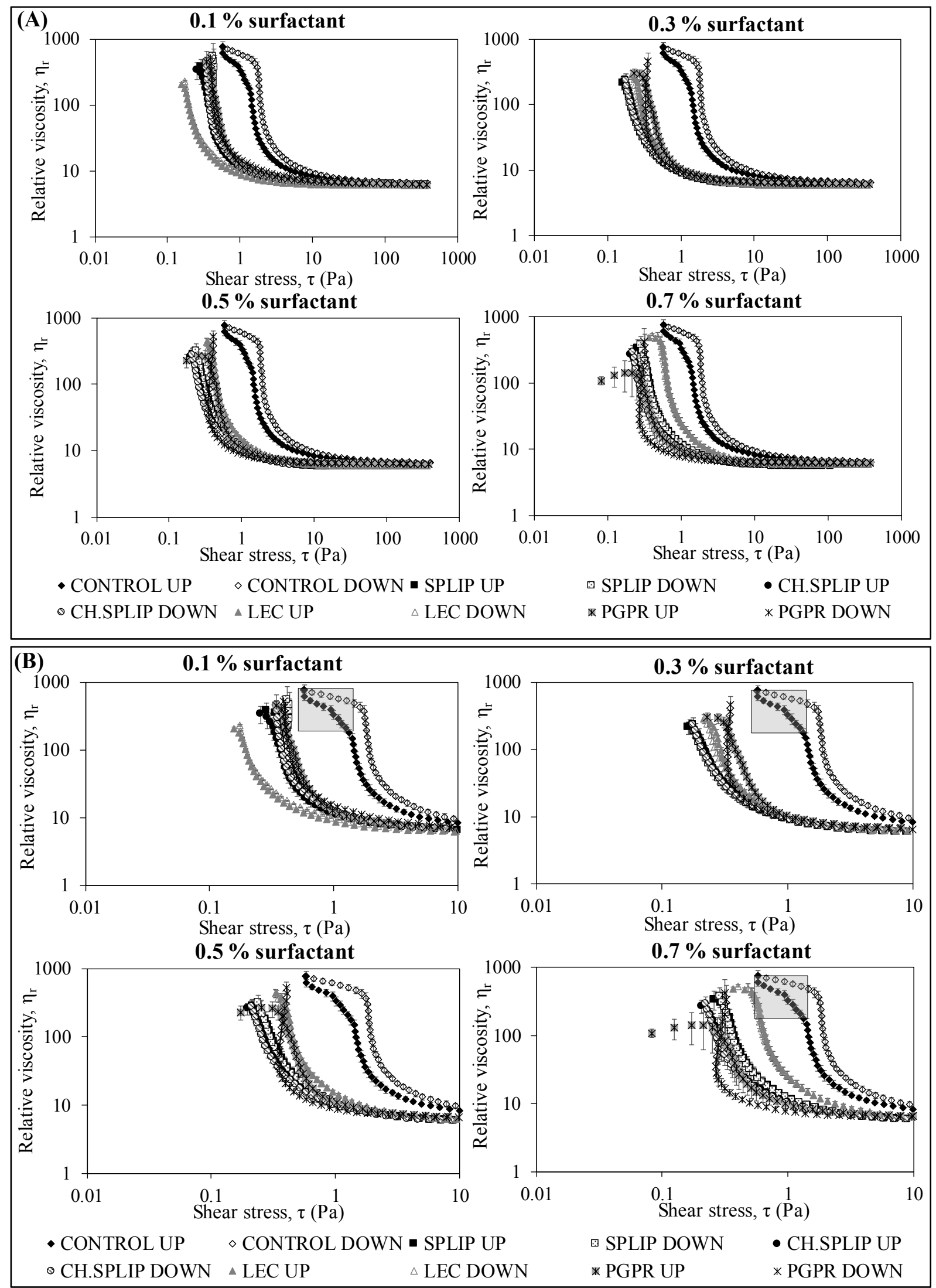

483 Fig. 6. (A) Relative viscosity curves of sugar/oil suspensions at sugar volume fraction of 0.37

484 as affected by the concentration of surfactant (mean $\pm 1.0, n=4)$. (B) Low shear region data to 
aid yield stress discussion. Data acquired during shear rate increase and decrease respectively are labeled "UP" and "DOWN". The greyed highlighted areas signify the transition from solid-like to liquid-like behavior.

Comparing the data traces acquired upon increasing shear (“UP”) versus decreasing shear ("DOWN"), it is evident that the control suspension and the suspensions containing more than $0.1 \%$ of PGPR were thixotropic. The decreasing shear ramp data at low shear stress $(0.05 \mathrm{~Pa}-0.5 \mathrm{~Pa})$ was below the values of the increasing shear ramp. The other surfactant containing systems were not thixotropic. At even lower shear stresses $(0.01-1 \mathrm{~Pa}$, depending on the sugar volume fraction), there was a point where the stress value of the decreasing ramp remained constant, while the apparent viscosity value increased. By that point, the sugar particles would strongly interact reducing the ability of the suspension to flow, thus increasing its apparent viscosity.

In samples with a sugar volume fraction of 0.33 , the critical stress value of the suspensions had increased. At a surfactant addition of $0.1 \%$, the critical stress was between $0.07 \mathrm{~Pa}$ and $0.25 \mathrm{~Pa}$, starting with lecithin as the lowest followed by the spinach lipids and PGPR. As the case of 0.28 sugar volume fraction, lecithin also showed the lowest critical stress value while PGPR showed the highest. At a surfactant addition of $0.3 \%$, similar trends were seen with the critical stress value being around $0.10-0.20 \mathrm{~Pa}$. At a surfactant addition of $0.5 \%$ and $0.7 \%$, the critical stress shown by PGPR was reduced to about $0.13 \mathrm{~Pa}$ and 0.05 Pa, respectively, with the apparent viscosity data in the shear thinning region approaching a plateau. The values for the SPLIP and CH.SPLIP systems remained constant at about 0.11 to $0.14 \mathrm{~Pa}$ for both of these higher concentrations.

Similar observations were seen for the suspensions with the highest sugar volume fraction (0.37). Lecithin showed the lowest critical stress value (around $0.2 \mathrm{~Pa}$ ) at $0.1 \%$ 
addition while the other surfactants imparted a critical stress of around $0.30-0.35 \mathrm{~Pa}$. At 0.3

$511 \%$ addition, all suspensions containing surfactant appeared to have a similar value of critical

512 stress, which was around $0.18-0.20 \mathrm{~Pa}$. At the two higher surfactant concentrations $(0.5 \%$

513 and $0.7 \%$ ), the critical stress of the suspension containing lecithin increased to $0.34 \mathrm{~Pa}$ and

$5140.52 \mathrm{~Pa}$, respectively. As was mentioned before, the initial data for PGPR at $0.5 \%$ and $0.7 \%$

515 had been influenced by the pre-shear sequence $\left(10 \mathrm{~s}^{-1}\right.$ for $\left.50 \mathrm{~s}\right)$ during which a higher shear

516 than recorded as the first data point $\left(0.01 \mathrm{~s}^{-1}\right)$ was applied. As a result, the first data point at

$5170.01 \mathrm{~s}^{-1}$ showed a lower apparent viscosity value than the subsequent data acquired at higher

518 shear. Therefore, the critical stress value for PGPR was taken where the data started to

519 decrease in apparent viscosity after that pre-shear affected area. This was at $0.30 \mathrm{~Pa}$ and 0.21

520 Pa for $0.5 \%$ and $0.7 \%$ addition, respectively. Systems containing SPLIP and CH.SPLIP

521 maintained a critical stress value of $0.20-0.25 \mathrm{~Pa}$ at the two higher concentrations of

522 surfactant.

Generally, all surfactants significantly affected the viscosity profile of the sugar/oil suspensions, with lecithin showing the highest reduction in apparent viscosity at the lowest concentration applied $(0.1 \%)$. The other surfactants only showed a comparable effect with lecithin at $0.3 \%$. Increasing concentration to more than $0.3 \%$ showed no further effect for spinach lipids but it was different for lecithin and PGPR. In the case of lecithin, the critical stress of the suspensions increased while in the case of PGPR, it was significantly lower at addition of $0.5 \%$ and $0.7 \%$. To compare the effect of the type and concentration of surfactant at different sugar volume fractions in terms of significant difference in the mean value of apparent viscosity and yield stress of suspensions, an evaluation following the recommendation by the International Office of Cocoa (IOC) (2000) was carried out. 
As recommended by the IOC (2000), the apparent viscosity at shear rate $40 \mathrm{~s}^{-1}(\eta 40)$ and the yield stress $(\tau)$ at shear rate $5 \mathrm{~s}^{-1}$ were extracted from the shear rheological data. The results are shown in Fig. 7. It can be seen that the addition of any surfactant into the sugar/oil systems caused a significant reduction $(\mathrm{p}<0.05)$ in the apparent viscosity and the yield stress of the suspensions irrespective of the sugar volume fraction.

PGPR had the weakest apparent viscosity-reducing effect of all surfactants included in this study, at all concentrations and for all three sugar phase volumes. The same behavior in comparison to lecithin has previously been reported (Rector, 2000; Schantz \& Rohm, 2005). In terms of apparent viscosity reduction, the two spinach lipid extracts performed in a similar way to lecithin, or slightly better. There were no statistically significant differences ( $p$ $>0.05)$ between the $\eta_{40}$ values of the two spinach lipid extracts at the same surfactant concentration and sugar phase volume.

The poor performance of PGPR as apparent viscosity reducing agent was not surprising, as PGPR is applied to chocolate to affect yield stress. However, the results in terms of yield stress reduction did not necessarily suggest that PGPR outperformed the other surfactant systems as may have been expected. In fact, the only statistically significant differences $(p<0.05)$ in yield stress between the systems containing surfactant at the same added concentration was lecithin lowering the yield stress further than PGPR at $0.1 \%$ for all three sugar phase volumes. Comparing the performance of surfactant at the lowest sugar volume fraction in terms of yield stress, CH.SPLIP lowered the yield stress further than lecithin and PGPR at addition of $0.3 \%$ and lecithin was not as effective as the other three surfactant systems at $0.5 \%$ as well as $0.7 \%$. PGPR was more effective than SPLIP and lecithin at $0.7 \%$ for all sugar volume fractions. At higher sugar volume fraction $(0.33$ and 0.37), CH.SPLIP performed comparably with PGPR in terms of yield stress at concentrations of $0.3 \%$ and above, while the effectiveness in lowering the apparent viscosity was more than 
560 lecithin at $0.5 \%$ and $0.7 \%$. Lecithin showed a reverse effect at high concentration,

561 increasing the yield stress and apparent viscosity value, as described before by Schantz and

562 Rohm (2005) and Beckett (2008). The reason for PGPR not standing out as much as

563 expected, at least in comparison to lecithin, may be due to the relatively low particle phase

564 volume included in this study, compared to real chocolate. As aforementioned, chocolate is

565 formulated at particle phase volumes of up to 0.75 . The lower values were selected here to

566 circumvent difficulties in reproducible preparation of the suspensions and occurrence of

567 measurement artifacts in the rheometer, in particular slip, may have compromised the value

568 of the data in view to reformulating chocolate.

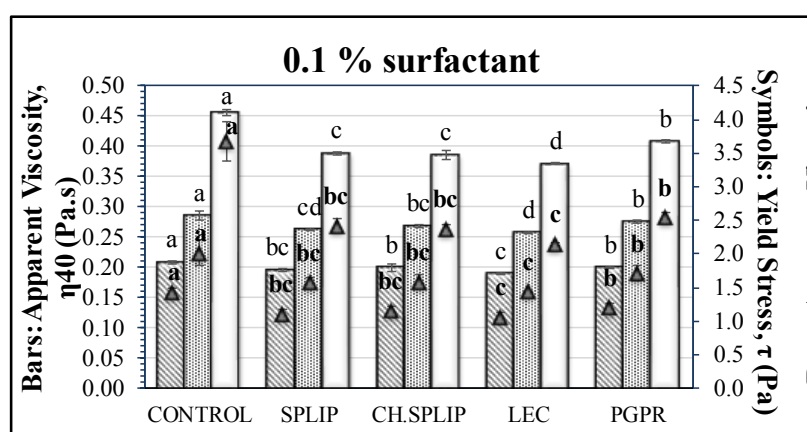

ه 0.28 volume fraction $\mathbf{0} 0.33$ volume fraction $\square 0.37$ volume fraction

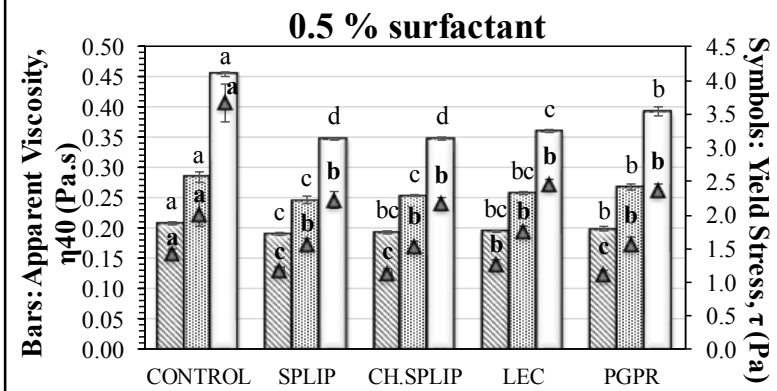

$\triangle 0.28$ volume fraction 0.33 volume fraction $\square 0.37$ volume fraction

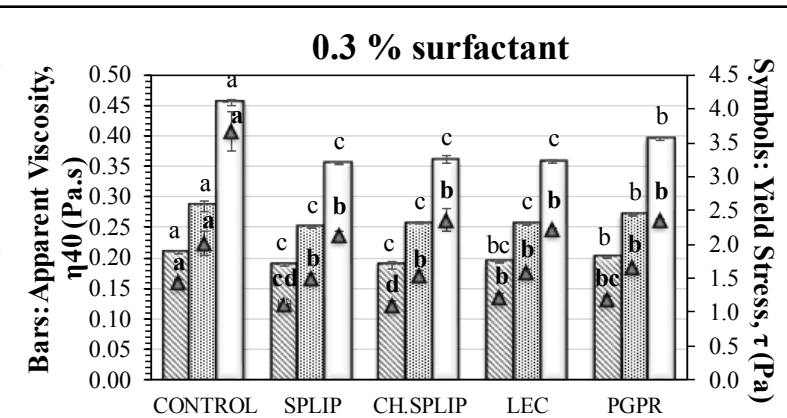

ه 0.28 volume fraction 0.33 volume fraction $\square 0.37$ volume fraction

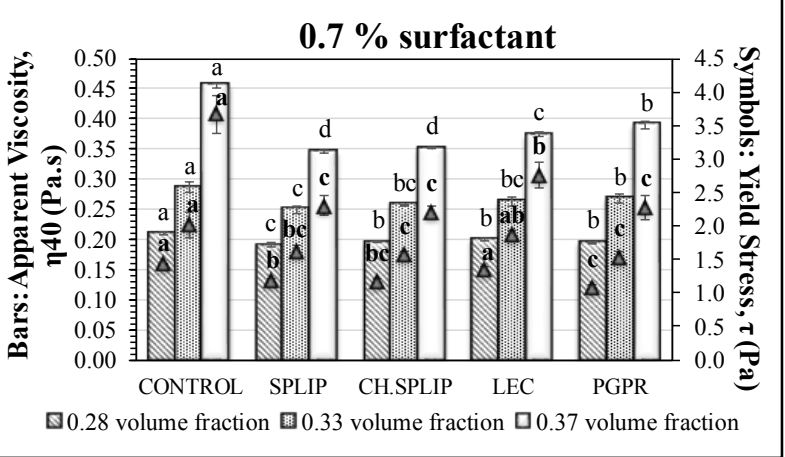

Fig. 7. Effect of spinach leaf lipid and chloroplast lipid in comparison to lecithin and PGPR

571 on the viscosity $\left(40 \mathrm{~s}^{-1}\right)$ and yield stress $\left(5 \mathrm{~s}^{-1}\right)$ of sugar/oil suspensions. Letters indicate

statistically significant difference $(p<0.05)$ between samples of same volume fraction. Bold

letters refer to yield stress.

$575 \quad$ 3.7. Behavior of surfactants at the interface of sugar and oil 
The behavior of lecithin at the interface of sugar and oil medium phase in modifying the flow properties of oil based suspensions was described as a head-tail emulsifier (Beckett, 2008; Middendorf, Juadjur, Bindrich, \& Mischnick, 2015). PGPR on the other hand was reported to not follow the principle of a head-tail emulsifier like lecithin (Ziegler, Garbolino,

580 \& Coupland, 2003). In the study by Middendorf et al. (2015), PGPR was seen to interact with

581 CB immobilized on the surface of sucrose forming pillow-like deposits between the individual sucrose particles, thereby separating these by stearic hindrance. The interaction of the immobilized CB and PGPR caused a space (depletion area) which needed to be filled by the CB from the bulk, thus enhancing the amount of immobilized fat instead of reducing (Middendorf et al., 2015). As a result, PGPR does not affect apparent viscosity significantly. The chemical structure of lecithin and PGPR are shown in Fig. 8. as the polar lipids (Mazliak, 1977). Due to the different molecular structure among these lipids, it is difficult to understand the behavior of spinach lipids at the interface of sugar and oil. MGDG has one galactose in its structure where it appears to have smaller head group than DGDG which has two molecules of galactose (Fig. 8). With the bulk lipophilic tails, MGDG molecules aggregate in the form of inverted rod like structure; not forming bilayers but adopting the hexagonal-II (HII) phase with the polar head group facing toward the center of the rod in water (Dörmann, 2013). On the other hand, DGDG with the larger size of polar head group adopts a cylindrical shape which in turn forms bilayers in pure water (Dörmann, 2013). SQDG and PG also adopt a cylindrical shape and form bilayers when dispersed in pure water (Kobayashi, 2016). 
60

602

603

604

605

606

607

608

609

610

611

612

613

614

615

616

617

618

619

620

621

622

623

624

625

626

627

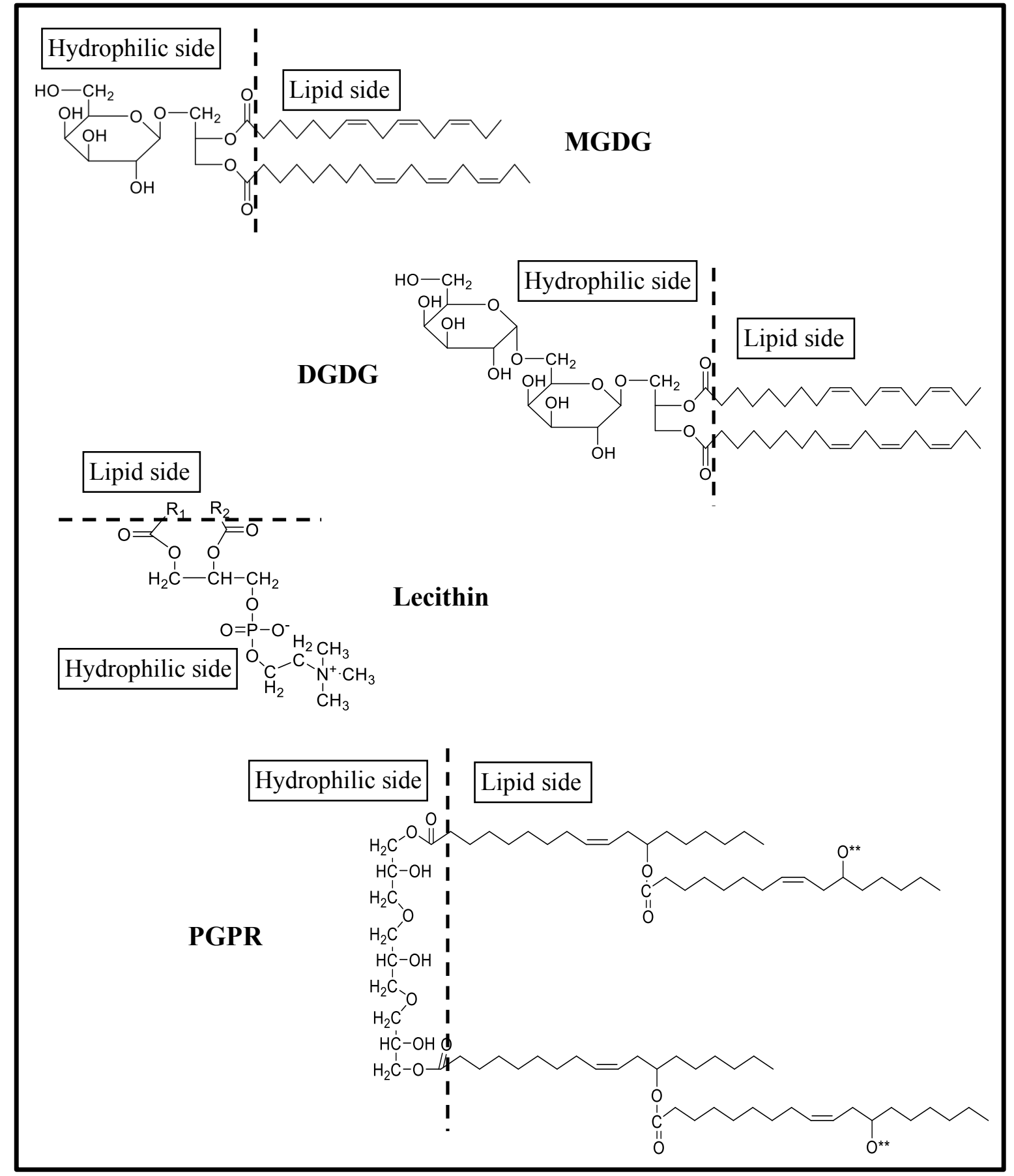

Fig. 8. Chemical structure of MGDG, DGDG, lecithin and PGPR. $R_{1}$ and $R_{2}$ are the fatty acids residues. The ${ }^{* *}$ on the PGPR structure denotes polyricinoleic acid chains.

The anionic SQDG and PG have been demonstrated to play an important role in maintaining the bilayer structure of neutral lipids in studies where screening out these lipids have resulted in the fusion of the single-shell vesicles and remaining lipids formed larger 
628

629

630

631

632

633

634

635

636

aggregates (Gounaris, Sen, Brain, Quinn, \& Williams, 1983). The non-bilayer phase of MGDG however, is understood to be a thermotropic mesophase where, at relatively low temperatures, MGDG forms a bilayer structure and on heating it can transform into a nonbilayer structure in excess water (Quinn, 2012). In this study, the process of extracting spinach lipids involved heating at $80{ }^{\circ} \mathrm{C}$ but it is hard to predict the possible behavior of the polar lipids when they are in a mixture, instead of their behavior individually. However, in other studies, when lipids were extracted from heated spinach extract MGDG was reported to have increased and the DGDG levels decreased compared to the unheated extract leading to a suggestion that further reactions involving DGDG lead to the formation of MGDG (Cho, Lee, Park, \& Lee, 2001; Fricker et al., 1975). This non-bilayer structure should be beneficial to give emulsifying effects on the sugar/oil suspension as the polar head of MGDG can adsorb to the hydrophilic surface of sugar while the tails are facing the oil. DGDG and some PC in the extract would also be expected to have a behavior like lecithin. Therefore, the apparent viscosity lowering effect by spinach lipids are suggested to be due to the combined action of MGDG, DGDG and PC. The negatively charged lipids of SQDG and PG (Fig. 9) are important to avoiding particle aggregation thus helping to maintain the low yield stress of the suspension and not showing the negative effect that lecithin gives when increasing the concentration.

6

(1)

8

9

(1)

1

2


Fig. 9. Chemical structure of PG and SQDG with the negative charge on the hydrophilic side.

$\mathrm{R}_{1}$ and $\mathrm{R}_{2}$ denote hydrocarbon chains of fatty acids.

\section{Conclusions}

The results presented in this study evidence the promising potential of lipids from spinach leaf and chloroplast for use as a rheology modifier in chocolate. The yield of lipid extracted from leaf was higher compared to chloroplast, albeit with a slightly different lipid composition. The glycolipids were the largest lipid group in the chloroplast fraction while the

673 leaf showed an equal amount of phospholipids and glycolipids. Both lipid types were surface active at very low concentrations. The rheological study revealed a comparable effect of both spinach lipid types as a rheological modifier of a sugar/oil suspension. Therefore, even though glycolipids were more concentrated in chloroplasts, due to a comparable efficiency in modifying the rheological properties, the higher yield of lipids from leaf mean that it would

678 be more beneficial to use the leaf extract so that the chloroplast isolation step can be omitted. 
680

681

682

683

684

685

686

687

688

689

690

691

692

693

694

695

696

697

698

699

700

701

702

703 same time showed a comparable effect with PGPR in reducing the yield stress of the suspensions. In conclusion, it appears worthwhile continuing to assess spinach lipid extract as a clean label rheology modifier in chocolate, complementing the present data acquired on a sugar/oil chocolate model.

\section{Acknowledgements}

This work was part of a PhD project with financial supported by The Ministry of Higher Education, Malaysia and the Universiti Malaysia Terengganu. Special thanks are extended to Division of Food, Nutrition and Dietetics staff, University of Nottingham (UK), who assisted with laboratory work and Ruth Price for proof reading the manuscript.

\section{References}

Afoakwa, E.O., Paterson, A., \& Fowler, M. (2008). Effects of particle size distribution and composition on rheological properties of dark chocolate. European Food Research and Technology, 226(6), 1259-1268. https://doi.org/10.1007/s00217-007-0652-6

Afoakwa, E. O., Paterson, A., Fowler, M., \& Vieira, J. (2009). Comparison of rheological models for determining dark chocolate viscosity. International Journal of Food Science and Technology, 44(1), 162-167. https://doi.org/10.1111/j.1365$\underline{2621.2008 .01710 . x}$

Allen, C. F., Good, P., Davis, H. F., Chisum, P., \& Fowler, S. D. (1966). Methodology for the separation o plant lipids and application to spinach leaf and chloroplast lamellae. Journal of the American Oil Chemists' Society, 43(4), 223-231. https://doi.org/10.1007/BF02641091 
704 Andersson, M.X., \& Dörmann, P. (2009). Chloroplast membrane lipid biosynthesis and

705

706 transport. The Chloroplast (pp. 125-158). Berlin, Heidelberg: Springer. https://doi.org/10.1007/978-3-540-68696-5_4.

Arnold, G., Schuldt, S., Schneider, Y., Friedrichs, J., Babick, F., Werner, C., \& Rohm, H. (2013). The impact of lecithin on rheology, sedimentation and particle interactions in oil-based dispersions. Colloids and Surfaces a-Physicochemical and Engineering Aspects, 418, 147-156. https://doi.org/10.1016/j.colsurfa.2012.11.006

Beckett, S. T. (2008). Science of Chocolate, 2nd Edition. United Kingdom: RSC Publishing. https://doi.org/10.1039/9781847558053.

Beckett, S. T. (2009). Chocolate Flow Properties. In S. T. Beckett (Ed.), Industrial Chocolate Manufacture And Use (pp. 224-246). United Kingdom: Wiley-Blackwell. https://doi.org/10.1002/9781118923597.ch11.

Benson, A. A. (1964). Plant membrane lipids. Annual Review of Plant Physiology, 15(1), 116. https://doi.org/10.1146/annurev.pp.15.060164.000245

Cho, E., Lee, J., Park, K., \& Lee, S. (2001). Effects of heat pretreatment on lipid and pigments of freeze-dried spinach. Journal of Food Science, 66(8), 1074-1079. https://doi.org/10.1111/j.1365-2621.2001.tb16083.x

Christiansen, K. (2014). PGPR, Polyglycerolpolyricinoleate, E476. Emulsifiers in Food Technology (pp. 209-230): John Wiley \& Sons, Ltd. https://doi.org/10.1002/9781118921265.ch9.

Christie, W. W. (2012). The Lipid Library. Preparation of lipid extracts from tissues. http://lipidlibrary.aocs.org/lipid-analysis/selected-topics-in-the-analysis-oflipids/preparation-of-lipid-extracts-tissues Accessed July 2015. 
Doehlert, D. C., Moreau, R. A., Welti, R., Roth, M. R., \& McMullen, M. S. (2010). Polar Lipids from Oat Kernels. Cereal Chemistry, 87(5), 467-474. https://doi.org/10.1094/cchem-04-10-0060

Doraiswamy, D., Mujumdar, A. N., Tsao, I., Beris, A. N., Danforth, S. C., \& Metzner, A. B. (1991). The Cox-Merz rule extended: a rheological model for concentrated suspensions and other materials with a yield stress. Journal of Rheology, 35(4), 647685. https://doi.org/10.1122/1.550184

Dörmann, P. (2013). Galactolipids in plant membranes. eLS. https://doi.org/10.1002/9780470015902.a0020100.pub2

Dörmann, P. \& Benning, C. (2002). Galactolipids rule in seed plants. Trends in Plant Science, 7(3), 112-118. https://doi.org/10.1016/S1360-1385(01)02216-6

Douce, R. (1974). Site of biosynthesis of galactolipids in spinach chloroplasts. Science, 183(4127), 852-853. https://doi.org/10.1126/science.183.4127.852

Douce, R., Holtz, R. B., \& Benson, A. A. (1973). Isolation and properties of the envelope of spinach chloroplasts. Journal of Biological Chemistry, 248(20), 7215-7222. https://www.jbc.org/content/248/20/7215.long Accessed June 2018

Evans, R., Jee, M. H., Sander, N. H., Smith, I. H., \& Gibson, R. K. (1991). United States Patent No.Retrieved from https://patentimages.storage.googleapis.com/02/95/d6/0d06ef0e37d6a4/US5026548.p df Accessed July 2018.

Fishwick, M. J., \& Wright, A. J. (1977). Comparison of methods for the extraction of plant lipids. Phytochemistry, 16(10), 1507-1510. https://doi.org/10.1016/0031$\underline{9422(77) 84011-9}$ 
750

751

752

753

Folch, J., Lees, M. \& Stanley, G. H. S. (1957). A simple method for the isolation and purification of total lipids from animal tissues. Journal of Biological Chemistry, 226(1), 497-509. http://www.jbc.org/content/226/1/497.full.pdf Accessed July 2015.

Fricker, A, Duben, R, Heintze, K, Panlas, K, \& Zohm, H. (1975). Influence of heat treatment of spinach at temperatures up to $100 \mathrm{C}$ on important constituents: Total lipids and glycolipids. Lebensm Wiss u Technol, 8, 172-186.

Gaonkar, A. G., \& Borwankar, R. P. (1991). Competitive adsorption of monoglycerides and lecithin at the vegetable oil-water interface. Colloids and Surfaces, 59, 331-343. https://doi.org/http://dx.doi.org/10.1016/0166-6622(91)80256-N

Gedi, M. A., Briars, R., Yuseli, F., Zainol, N., Darwish, R., Salter, A. M., \& Gray, D. A. (2017). Component analysis of nutritionally rich chloroplasts: recovery from conventional and unconventional green plant species. Journal of Food Science and Technology, 54(9), 2746-2757. https://doi.org/10.1007/s13197-017-2711-8

Goncalves, E. V., \& Lannes, S. C. D. (2010). Chocolate rheology. Ciencia E Tecnologia De Alimentos, 30(4), 845-851. https://doi.org/10.1590/s0101-20612010000400002

Gounaris, K., Mannock, D. A., Sen, A., Brain, A. P. R., Williams, W. P., \& Quinn, P. J. (1983). Polyunsaturated fatty acyl residues of galactolipids are involved in the control of bilayer/non-bilayer lipid transitions in higher plant chloroplasts. Biochimica et Biophysica Acta (BBA) - Biomembranes, 732(1), 229-242. https://doi.org/http://dx.doi.org/10.1016/0005-2736(83)90207-9

Gounaris, K., Sen, A., Brain, A. P. R., Quinn, P. J., \& Williams, W. P. (1983). The formation of non-bilayer structures in total polar lipid extracts of chloroplast membranes. Biochimica et Biophysica Acta (BBA)-Biomembranes, 728(1), 129-139. https://doi.org/10.1016/0005-2736(83)90445-5 
774 Gülseren, İ., \& Corredig, M. (2012). Interactions at the interface between hydrophobic and hydrophilic emulsifiers: Polyglycerol polyricinoleate (PGPR) and milk proteins, studied by drop shape tensiometry. Food Hydrocolloids, 29(1), 193-198. https://doi.org/http://dx.doi.org/10.1016/j.foodhyd.2012.03.010

International Office of Cocoa, IOC. (2000). Viscosity of Cocoa and Chocolate Products Analytical Methods 46 (Available from CAOBISCO, rue Defacqz 1, B-1000 Bruxelles, Belgium).

Jaime, L., Vazquez, E., Fornari, T., Lopez-Hazas, M. D., Garcia-Risco, M. R., Santoyo, S., \& Reglero, G. (2015). Extraction of functional ingredients from spinach (Spinacia oleracea L.) using liquid solvent and supercritical CO2 extraction. Journal of the Science of Food and Agriculture, 95(4), 722-729. https://doi.org/10.1002/jsfa.6788

Kaimainen, M., Ahvenainen, S., Kaariste, M., Jarvenpaa, E., Kaasalainen, M., Salomaki, M., Salonen, J., \& Huopalahti, R. (2012). Polar lipid fraction from oat (Avena sativa): characterization and use as an o/w emulsifier. European Food Research and Technology, 235(3), 507-515. https://doi.org/10.1007/s00217-012-1780-1

Kates, M., \& Eberhardt, F. M. (1957). Isolation and fractionation of leaf phosphatides. Canadian Journal of Botany, 35(6), 895-905. https://doi.org/10.1139/b57-074

Kobayashi, K. (2016). Role of membrane glycerolipids in photosynthesis, thylakoid biogenesis and chloroplast development. Journal of Plant Research, 129(4), 565-580. https://doi.org/10.1007/s10265-016-0827-y

Mazliak, P. (1977). Glyco- and Phospholipids of Biomembranes in Higher Plants. In M. Tevini \& H.K. Lichtenthaler (Eds.), Lipids and Lipid Polymers in Higher Plants (pp. 48-74). Berlin, Heidelberg: Springer Berlin Heidelberg. https://doi.org/10.1007/978$\underline{3-642-66632-233}$. 
Melo, N., Tavares, R. M., Morais, F., Barroso, J. G., \& Pais, M. S. S. (1995). Lipid composition of thylakoid membranes from leaves and regreened spathes of Zantedeschia aethiopica. Phytochemistry, 40(5), 1367-1371. https://doi.org/10.1016/0031-9422(95)00506-3

Menke, W. (1938). Untersuchungen über das Protoplasma grüner Pflanzenzellen. I. Isolierung von Chloroplasten aus Spinatblättern. Hoppe-Seyler's Zeitschrift für physiologische Chemie, 257(1), 43-48. https://doi.org/10.1515/bchm2.1938.257.1.43

Middendorf, D., Juadjur, A., Bindrich, U., \& Mischnick, P. (2015). AFM approach to study the function of PGPR's emulsifying properties in cocoa butter based suspensions. Food Structure, 4, 16-26. https://doi.org/10.1016/j.foostr.2014.11.003

Neufeld, Elizabeth F., \& Hall, Clara W. (1964). Formation of galactolipids by chloroplasts. Biochemical and Biophysical Research Communications, 14(6), 503-508. https://doi.org/https://doi.org/10.1016/0006-291X(64)90259-1

Nishimura, M., Graham, D., \& Akazawa, T. (1976). Isolation of intact chloroplasts and other cell organelles from spinach leaf protoplasts. Plant Physiology, 58(3), 309-314. https://doi.org/10.1104/pp.58.3.309

Osborn, S. (2015). Labelling relating to natural ingredients and additives. In P. Berryman (Ed.), Advances in Food and Beverage Labelling (pp. 207-221): Woodhead Publishing. https://doi.org/10.1533/9781782420934.3.207.

Östbring, K., Rayner, M., Albertsson, P.Â., \& Erlanson-Albertsson, C. (2015). Heat-induced aggregation of thylakoid membranes affect their interfacial properties. Food \& Function, 6(4), 1310-1318. https://doi.org/10.1039/C4FO01074D

Quinn, P. J. (2012). Lipid-lipid interactions in bilayer membranes: Married couples and casual liaisons. Progress in Lipid Research, 51(3), 179-198. https://doi.org/http://dx.doi.org/10.1016/j.plipres.2012.01.001 
823 Rayner, M., Emek, S. C., Gustafssona, K., Erlanson-Albertsson, C., \& Albertsson, P. Â.

824

825

826

827

828

829

830 (2011). A novel emulsifier from spinach with appetite regulation abilities. In G. Saravacos, P. Taoukis, M. Krokida, V. Karathanos, H. Lazarides, N. Stoforos, C. Tzia, \& S. Yanniotis (Eds.), 11th International Congress on Engineering and Food (Vol. 1, pp. 1431-1438). Amsterdam: Elsevier Science Bv. https://doi.org/10.1016/j.profoo.2011.09.212.

Rayner, M., Ljusberg, H., Emek, S. C., Sellman, E., Erlanson-Albertsson, C., \& Albertsson, P. Â. (2011). Chloroplast thylakoid membrane-stabilised emulsions. Journal of the Science of Food and Agriculture, 91(2), 315-321. https://doi.org/10.1002/jsfa.4187

Rector, D. (2000). Chocolate-controlling the flow. The Manufacturing Confectioner, 80, 63 70. http://www.gomc.com/firstpage/200005063.pdf Accessed July 2018.

Sahasrabudhe, M. R. (1979). Lipid composition of oats (Avena sativa L.). Journal of the American Oil Chemists' Society, 56(2), 80. https://doi.org/10.1007/BF02914274

Schantz, B., \& Rohm, H. (2005). Influence of lecithin-PGPR blends on the rheological properties of chocolate. Lwt-Food Science and Technology, 38(1), 41-45. https://doi.org/10.1016/j.lwt.2004.03.014

Servais, C, Ranc, H, \& Roberts, I. D. (2003). Determination of chocolate viscosity. Journal of Texture Studies, 34(5-6), 467-497. https://doi.org/10.1111/j.1745$\underline{\text { 4603.2003.tb01077.x }}$

Siebertz, H. P., Heinz, E., Linscheid, M., Joyard, J., \& Douce, R. (1979). Characterization of lipids from chloroplast envelopes. European Journal of Biochemistry, 101(2), 429438. https://doi.org/10.1111/j.1432-1033.1979.tb19736.x

Taylor, J. E, Van Damme, I, Johns, M. L., Routh, A. F., \& Wilson, D. I. (2009). Shear rheology of molten crumb chocolate. Journal of Food Science, 74(2), E55-E61. https://doi.org/10.1111/j.1750-3841.2008.01041.x 
van Nieuwenhuyzen, W. (2010). Lecithin and Other Phospholipids. In M. Kjellin \& I. Johansson (Eds.), Surfactants from Renewable Resources (pp. 191 - 211). Great Britain: A John Wiley and Sons, Ltd., Publication. https://doi.org/10.1002/9780470686607.ch10.

Whitaker, B. D. (1986). Fatty-acid composition of polar lipids in fruit and leaf chloroplasts of "16:3"- and "18:3"-plant species. Planta, 169(3), 313-319. https://doi.org/10.1007/bf00392125

Wintermans, J. F. G. M. (1960). Concentrations of phosphatides and glycolipids in leaves and chloroplasts. Biochimica Et Biophysica Acta, 44, 49-54. https://doi.org/http://dx.doi.org/10.1016/0006-3002(60)91521-3

Yao, L., Gerde, J. A., \& Wang, T. (2012). Oil extraction from microalga Nannochloropsis sp. with isopropyl alcohol. Journal of the American Oil Chemists' Society, 89(12), 22792287. https://doi.org/10.1007/s11746-012-2124-9

Youngs, V. L., Puskulcu, M., \& Smith, R. R. (1977). Oat lipids. I. Composition and distribution of lipid components in two oat cultivars. Cereal Chemistry, 54, 803-812. https://www.aaccnet.org/publications/cc/backissues/1977/Documents/chem54_803.pd f Accessed July 2018.

Yunoki, K., Sato, M., Seki, K., Ohkubo, T., Tanaka, Y., \& Ohnishi, M. (2009). Simultaneous quantification of plant glyceroglycolipids including sulfoquinovosyldiacylglycerol by HPLC-ELSD with binary gradient elution. Lipids, 44(1), 77-83. https://doi.org/10.1007/s11745-008-3248-4

Ziegler, G. R., Garbolino, C., \& Coupland, J. N. (2003). The influence of surfactants and moisture on the colloidal and rheological properties of model chocolate dispersions. Paper presented at the 3rd International Symposium on Food Rheology and Structure, Zurich, Switzerland. 
873

874

875

876 